\title{
Src family kinases, adaptor proteins and the actin cytoskeleton in epithelial-to-mesenchymal transition
}

\author{
Maria A. Ortiz ${ }^{1,2}$, Tatiana Mikhailova ${ }^{1}$, Xiang Li ${ }^{1,2}$, Baylee A. Porter ${ }^{1,2}$, Alaji Bah ${ }^{1}$ and Leszek Kotula ${ }^{1,2^{*}}$ (0)
}

\begin{abstract}
Over a century of scientific inquiry since the discovery of v-SRC but still no final judgement on SRC function. However, a significant body of work has defined Src family kinases as key players in tumor progression, invasion and metastasis in human cancer. With the ever-growing evidence supporting the role of epithelial-mesenchymal transition (EMT) in invasion and metastasis, so does our understanding of the role SFKs play in mediating these processes. Here we describe some key mechanisms through which Src family kinases play critical role in epithelial homeostasis and how their function is essential for the propagation of invasive signals.
\end{abstract}

Keywords: Src family kinases, Epithelial-to-mesenchymal transition, Treatment resistance, Metastasis, Invasion, Unique domain, Actin cytoskeleton

\section{Background}

SRC is the transforming product of the first identified oncogenic virus and the prototype for SRC family kinases (SFKs). Pioneering work conducted by Peyton Rous in 1911 on viral SRC (v-SRC), sparked years of research seeking to understand SRC-driven oncogenesis [1, 2]. Initial observations showed that SRC activity was positivetily correlated with cancer progression into a metastatic state. This prompted the idea that SRC function may be essential for the development of metastasis and invasion [3]. Since then, SFKs have been identified as key players in tumor progression, invasion and metastasis in a variety of different cancers.

Currently, the mainstay hypothesis which explains the cellular processes involved in the regulation of invasiveness and metastasis is the epithelial-to-mesenchymal transition (EMT). The EMT refers to a cellular program that allows epithelial cells to obtain

*Correspondence: kotulal@upstate.edu

${ }^{1}$ Department of Biochemistry and Molecular Biology, SUNY Upstate Medical University, Syracuse, USA

Full list of author information is available at the end of the article mesenchymal features, which has been shown to generate more invasive and treatment-refractory cancers. While EMT is important in a variety of processes such as embryonic development (Type I EMT) and wound healing (Type II EMT); this review will focus on EMT in carcinogenesis, metastasis and invasion (type III EMT) [4]. Moreover, it is important to note that while EMT in embryogenesis results in a fully differentiated mesenchymal state, in the context of carcinogenesis, partial EMT is most commonly observed giving rise to cancer cells that exhibit both epithelial and mesenchymal features $[5,6]$. With the evergrowing body of literature supporting the role of the epithelial-mesenchymal transition (EMT) in invasion and metastasis, so does our understanding of the role SFKs play in mediating these processes [7]. Here, we describe the mechanisms through which SFKs regulate epithelial homeostasis and how SFK dysregulation is key in promoting the EMT in various cancer. Moreover, we will explore the role of SFKs in mediating treatment resistance and the implications of this resistance for the future of SFK inhibitors in the treatment of metastatic diseases. original author(s) and the source, provide a link to the Creative Commons licence, and indicate if changes were made. The images or other third party material in this article are included in the article's Creative Commons licence, unless indicated otherwise in a credit line to the material. If material is not included in the article's Creative Commons licence and your intended use is not permitted by statutory regulation or exceeds the permitted use, you will need to obtain permission directly from the copyright holder. To view a copy of this licence, visit http://creativecommons.org/licenses/by/4.0/. The Creative Commons Public Domain Dedication waiver (http://creativeco mmons.org/publicdomain/zero/1.0/) applies to the data made available in this article, unless otherwise stated in a credit line to the data. 


\section{Src family kinases}

Src family kinases (SFKs) are non-receptor tyrosine kinases involved in the regulation of important cellular functions such as cell proliferation, differentiation, apoptosis, migration, and metabolism $[8,9]$. The vertebrate Src kinase family is composed of nine members, namely, SRC, LCK, LYN, BLK, HCK, FYN, FGR, YES, and YRK. Please note that YRK is only expressed in chickens, so we will omit it in subsequent sections in order to focus on the role of SFKs in human cancers. It is curious that the YRK protein kinase in chickens is $95 \%$ identical to the FGR protein kinase in black swans. Based on the prolife of YRK expression, the Yrk gene seems to be very similar to the FGR gene in vertebrates (Fig. 1, top panel). Moreover, initial characterization of SFKs included tyrosine kinases such as SRM and FRG, however, amino acid sequence and intron/exon structural analysis placed these kinases in the Brk kinase family $[10,11]$.

\section{SFK structure, localization and function}

Src family kinases are modular proteins that share a common domain architecture consisting of both intrinsically disordered regions (IDRs) and folded domains. At the N-terminus is an intrinsically disordered membrane-anchoring, myristoylated Src homology domain 4 (SH4), followed by regulatory folded domains $\mathrm{SH} 3$ and $\mathrm{SH} 2$, as well as an enzymatically active tyrosine kinase domain (SH1) connected to an intrinsically disordered C-terminal regulatory region $[8,9,12,13]$. The SH3 and SH4 domains are linked by another IDR termed Unique domain (UD) $[14,15]$. The structure and functions of the folded SH3, SH2, and SH1 kinase domains of SFKs have been extensively studied in exquisite detail [9]. However, in the past two decades, emerging structural and biochemical studies have also started to elucidate the crucial role of the UDs, and the synergy of the UD and the folded domains, in the regulation of SFK subcellular localization and activity $[8,16-18]$. Unlike the folded domains that are highly conserved across the whole Src kinase family, the UDs of the various SFK have quite variable lengths and amino acid sequence composition [8, 14]. However, the UDs of the individual kinases are surprisingly highly conserved among species and to demonstrate the physiological importance of the UD in SFKs, previous studies show that swapping the UD of SRC and YES interchanges their functional specificity [19-21]. The UD of SRC, which has been the subject of the most intense structural, biophysical and biochemical investigations, is shown to adopt a compact, yet highly dynamic, intramolecular fuzzy structure that uses the $\mathrm{SH} 3$ domain as a scaffold [22]. However, further studies by Miguel Pons and colleagues suggests that, despite their lack of conservation, the UDs of the SFKs shares a common mechanism for connecting the disordered and structured domains within the SFKs. Indeed, the existence of multiple posttranslational modifications, such as phosphorylation, that modulate the biologically relevant inter-and intra-molecular interactions of UDs of SFKs reinforces the critical functions played by the intrinsically disordered UD in regulating the localization and activities of SFKs [8, 22].

Regulation of membrane localization is a critical mechanism governing the biological functions of SFKs [23]. Thus, cells have evolved multiple interdependent mechanisms, which are mediated via intra- and intermolecular interactions, for regulating of SFK subcellular localization to the plasma and intracellular membranes; to the cytoskeleton, signaling foci, subcellular compartments and organelles as well as to the extracellular matrix $[16,23,24]$. First among these regulatory mechanisms is a critical N-terminal sequence (Met-Gly-X-X-X-Ser/ $\mathrm{Thr}$ ) in the SH4 domain that allows for irreversible cotranslational attachment of a myristate group -14 carbon saturated lipid [25]. Before translated protein products are released from the ribosome, a myristic acid-derived myristoyl group is attached to the $\mathrm{N}$-terminal glycine by $\mathrm{N}$-myristoyltransferase enzymes. This modification allows water-soluble proteins to associate with hydrophobic membranes. In addition to myristoylation, membrane targeting of SFKs is further facilitated by the presence of positively charged residues that allow for electrostatic interaction with negatively charged head groups of the membrane phospholipids (Fig. 2). Both of these structural components are essential for membrane anchoring as their alterations are associated with altered SFK-mediated cell signaling [26].

Another important membrane-anchoring mechanism that utilizes post-translational modification which occurs at the SH4 domain of many SFKs is palmitoylation-a reversible attachment of deprotonated fatty acid group to a cysteine residue. It turns out, palmitoylation is dependent on myristoylation, and while all SFKs are myristoylated, SRC and BLK lack the N-terminal cysteine necessary to complete the myr-Gly-Cys motif required for palmitoylation $[25,27,28]$. Interestingly, the interaction of SFKs with lipid membranes is not restricted to the post-translational modifications (PTMs)-facilited anchors and amino acid sequence composition of the SH4 domain alone. In 2013, Pérez et al. discovered that a partially structured region within the UD of SRC, aptly named unique lipid binding region (ULBR), that can interact with lipids in a T37 and S75 phosphorylationdependent manner [16]. Moreover, there is evidence suggesting the existence of a coupling mechanism between the lipid binding properties of the ULBR and SH4 domain binding. Furthermore, members of the SFKs can use their 


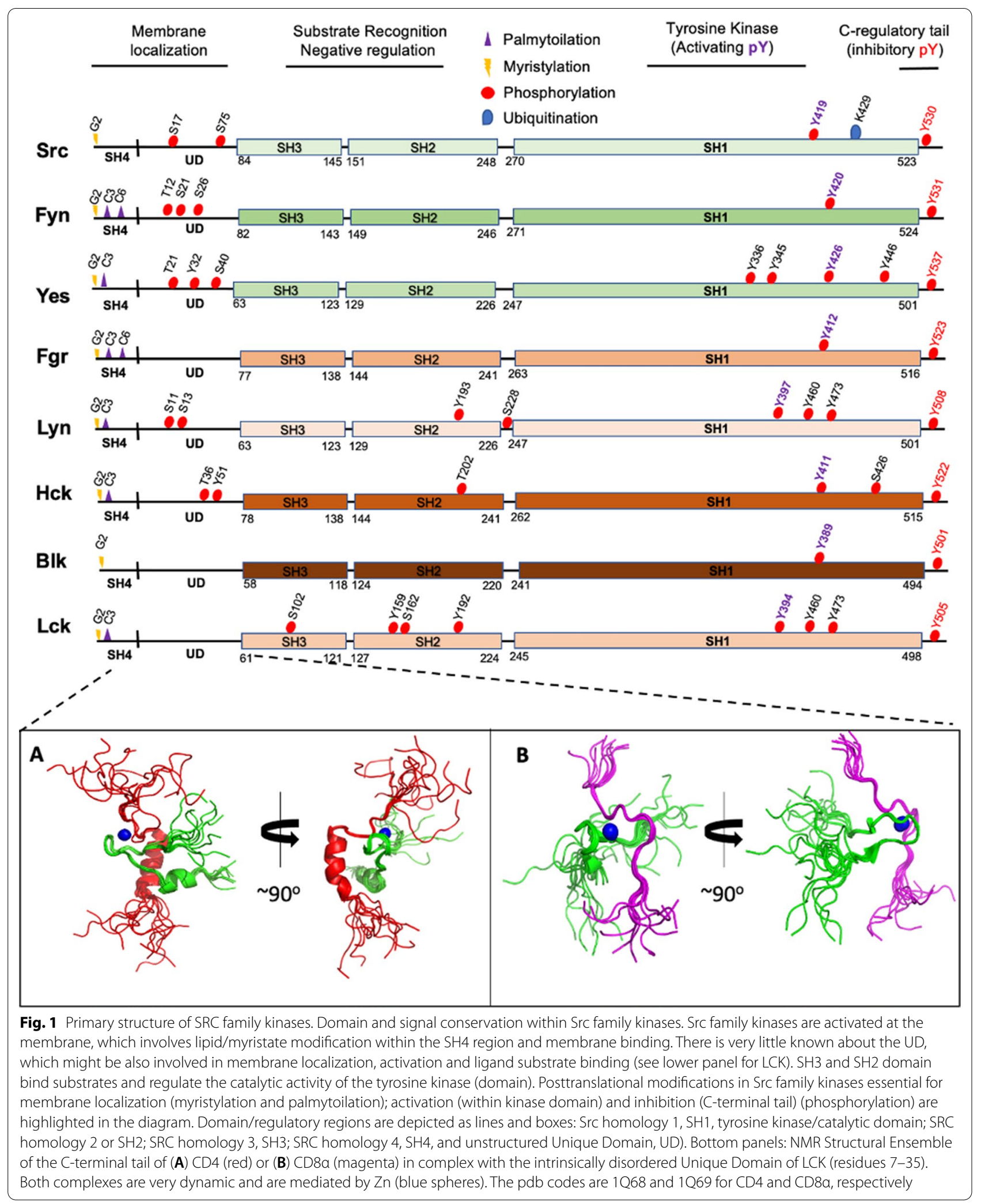




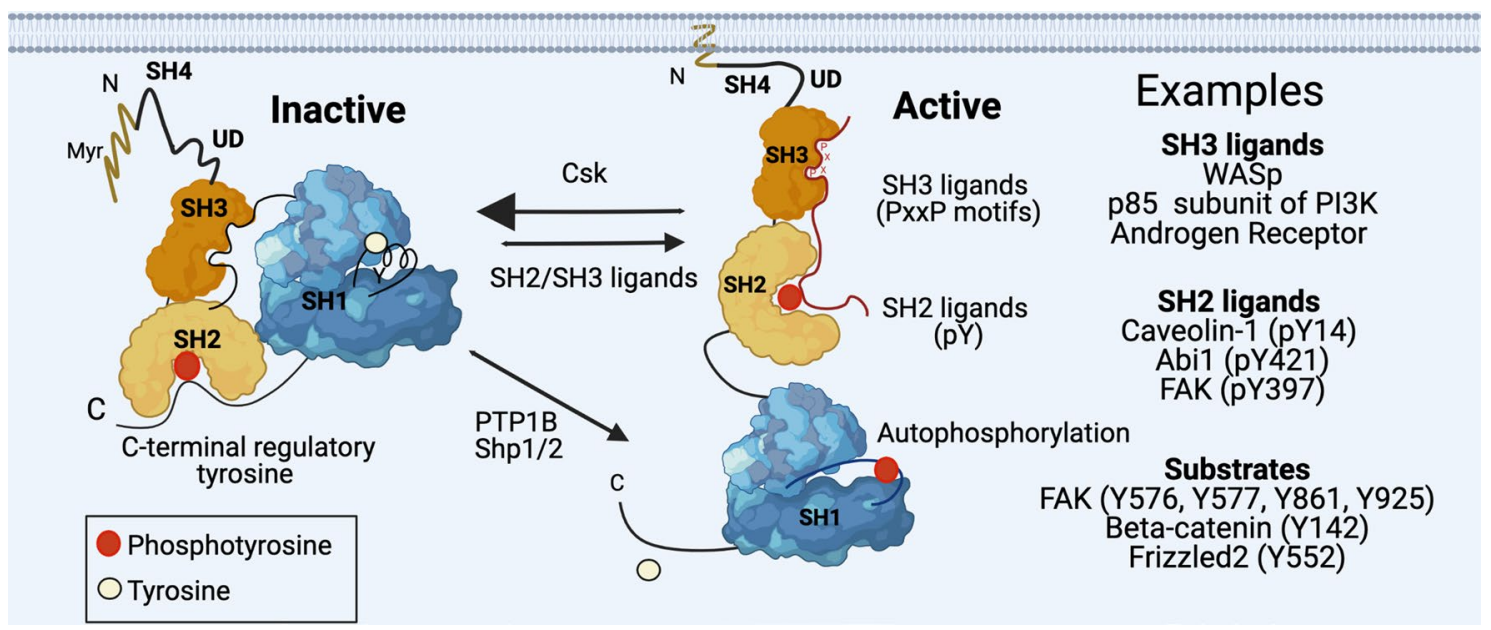

Fig. 2 Conformational changes associated with Src family kinase activation and inhibition. Left, inactive conformation of Src family kinases is associated with lack of membrane binding, lack of phosphorylation of the activation loop tyrosine, phosphorylation of the C-terminal regulatory region tyrosine; and characterized by a "closed conformation". The closed conformation is maintained through inhibitory SH3-SH2 domain interactions with the catalytic domain ( $\mathrm{SH} 1$ ), and the C-terminal regulatory phosphotyrosine interaction with the $\mathrm{SH} 2 \mathrm{domain}$. These interactions prevent ligand substrate binding. Right, Active "open" conformation allows for ligand binding and autophosphorylation of the activation loop tyrosine. The balance of active/inactive conformation is regulated by Csk that promotes phosphorylation of C-terminal tyrosine; and its dephosphorylation by PTP1B/Shp1/2. Ligand binding facilitates activation but may also regulate kinase activity through restricting access (competitive inhibition) to the active catalytic domain. Examples of SRC kinase ligands/substrates are listed on the far right. Created with BioRender. com

modular domain architecture to localize to plasma membranes and intracellular membranes via protein:protein interactions with membrane-anchored receptors. For instance, LCK utilizes its UD to mediate its association with the intrinsically disordered tails of the cell membrane-anchored $\mathrm{T}$ cell co-receptors $\mathrm{CD} 4$ or $\mathrm{CD} 8 \alpha$ by undergoing a disorder-to-order transition to form a compact heterodimeric zinc-mediated complex (Fig. 1, bottom panel) [29]. In addition, Salter and colleagues have also demonstrated that NADH dehydrogenase subunit 2 (ND2) anchors SRC kinase to $\mathrm{N}$-methyl D-aspartate receptors (NMDARs) at post-synaptic densities (PSDs) in the hippocampus via an interaction involving SRC UD residues 40-49 and ND2 residues 239-321 [30, 31].

Following the multifunctional, intrinsically disordered UD are the folded reguratory $\mathrm{SH} 3$ and $\mathrm{SH} 2$ domains, which can also be used to anchor SFKs to membranebound and non-membrane-bound signaling complexes through interactions involving binding partners with proline-riched and phosphotyrosine-containing motifs, respectively $[32,33]$. Interestingly, these regulatory $\mathrm{SH} 3$ and $\mathrm{SH} 2$ domains are also found in many other signaling proteins, where they are utilized to help assemble membraneless, liquid-liquid phase separated organelles via transient multivalent interactions [34].

Next, we will briefly describe the structure and binding mechanisms used by these regulatory domains to control the kinase activity of SFKs. SH3 domains are small, approximately sixty amino acid-residue folded $\beta$-barrels, consisting of five antiparallel strands that mediate protein:protein interactions by binding to proline-rich sequences that can adopt a left-handed helical conformation [35]. SH3 domains contain two prominent loops, known as the RT and n-SRC loops, that lie at either end of a surface generated by aromatic and hydrophobic residues that make up the recognition site for PxxP motifs. For instance, as part of the regulatory intramolecular interactions in SFKs, the linker between the SH2 domain and SH1 kinase domain contains a proline residue that interacts with the $\mathrm{SH} 3$ domain, thereby stabilizing the 'closed' inactive conformation (Fig. 2) [9, 36].

In contrast, the $\mathrm{SH} 2$ domains are modular phosphotyrosine-binding domains that consists of an approximately 100 amino acid residues, which fold into structure with two $\alpha$-helices (a1 and a2) that packed against each side of a central three-stranded $\beta$-sheet [37]. The SH2 domain structure has a conserved argine-containing recognition pocket for binding phosphotyrosine residues and another pocket for binding hydrophobic residues C-terminal to the phosphotyrosine motif. Interestingly, $\mathrm{SH} 2$ domains can bind to a variety of phosphotyrosinecontaining sequences that do not contain the consensus pYEEI motif, because residues well beyond the vicinity of the phosphotyrosine modification also contribute significantly to the extended binding interface. One predominant mechanism for controlling the kinase activity 
of SFKs is the formation of an intramolecular interaction between the $\mathrm{SH} 2$ domain and a pTyr residue located at the intrinsically disordered C-terminal regulatory region, resulting in a 'closed' inactive conformation [9, 38]. Hence, these conformational states are regulated by the balanced activity of the kinase Csk, promoting the inactive conformation, and phosphatases such as PTP1B and Shp1/2, which promote displacement of this interaction due to dephosphorylation of this phosphotyrosine. In addition, competitive binding from signaling proteins containing phosphotyrosine motifs, lead to an 'open' active conformation of SFKs (Fig. 2). In another major activation mechanism, SRC and other SFKs can undergo intermolecular autophosphorylation of a Tyr residue located at the activation loop of the $\mathrm{SH} 1$ catalytic domain to enhance kinase activity. The SH1 domain, which is the catalytic center of the kinase, contains two 'lobes': a small lobe found in all protein kinases is generated by a fivestranded antiparallel $\beta$-sheet and an important regulatory $\alpha \mathrm{C}$-helix, while the large lobe of the kinase domain consists of mainly conserved $\alpha$-helical segments. The active site of the kinase domain lies within a cleft nestled between the small $\mathrm{N}$-lobe and the large $\mathrm{C}$-lobe. As described above, there are multiple intra- and intermolecular regulatory mechanisms that control substrate specificity and activity of SFK kinase domain. These mechanisms include destabilization of the intramolecular interactions involving the $\mathrm{SH} 3$ and $\mathrm{SH} 2$ domains by phosphatases, kinases, scaffolding proteins, and substrates with PxxP- and/or phosphotyrosine-containing motifs that shift the conformational equilibrium to an 'open' active state (Fig. 2) [9, 38].

In addition to controlling their membrane localization and activities at the protein level, the function of SFKs is also regulated by controlling their transcriptional and translational expression in various tissues, and cell-types (Fig. 3) as well as their differential sorting to various subcellular compartments and the extracellular matrix. For instance, SRC, FYN, LYN and YES are widely expressed, while other members have a more restricted expression pattern, especially to cells of hematopoietic origin $[39,40]$. Furthermore, expression levels of SFKs vary among cell types, for example, while SRC is ubiquitious, its expression is highest in platelets, neurons, and osteoclasts (Brown \& Cooper 1996).

Moreover, coexpression of different SFKs may vary among cellular subtypes and subcellular compartments (Fig. 3). Work by Kuga and colleagues showed that while SRC, YES and LYN are all co-expressed in HeLa cells, they were activated at different levels by the cyclindependent kinase 2 (Cdc2) during the $\mathrm{M}$ phase of mitosis [40]. As discussed above, subcellular localization plays a critical role in the function of SFKs. Indeed, SFKs have been found in a variety of different subcellular compartments such as caveolae, focal adhesions, endosomes, lysosomes and nucleus [41-45]. In addition to its established intracellular functions, there is emerging evidence showing that the prototypic SFK, SRC, also has extracellular functions such as regulation of MMP2 activity through phosphorylation of its inhibitor, the tissue inhibitor of metalloproteinases 2 (TIMP-2) [46]. A recent study by Tanaka et al., show that SRC extracellular secretion was regulated by ubiquitination at Lys429, a highly conversed residue among all SFK members, suggesting this mechanism may also be applicable to other SFK members [47]. Taken together, these multiple regulatory mechanisms demonstrate that there is an intricate cellular network of lipid-modifying enzymes, kinases, phosphatases, binding partners and substrates from diverse signaling pathways that coordinate to tighly control the localization and to fine-tune the level of SFK catalytic activity. Thus, like in other modular proteins [48], the functions of the IDRs and folded domains within the SFKs synergize to precisely control the biological functions of SFKs. However, when that synergy is disrupted due to mutagenesis of the cognate proteins involved or hijacked by disease-causing agents, devasting maladies like cancer can result [49].

\section{Src family kinases in the epithelial mesenchymal transition (EMT)}

Src family kinases have been shown to interconnect a variety of different cellular pathways which promote invasion and metastasis. Unsurprisingly, these pathways are also critical in the propagation and initiation of the epithelial-to-mesenchymal transition [7]. The epithelialto-mesenchymal transition (EMT) is a cellular program which enables epithelial cells to acquire mesenchymal features and has been shown to be critical in embryonic development, wound healing, and malignant progression [50]. Moreover, the EMT has been linked to acquisition of treatment resistance in a variety of malignancies including solid tumors and hematologic malignancies, all of which underscore its clinical significance [51, 52]. Interestingly, the stromal tissue which surrounds a carcinoma is not much different than that of stroma in non-tumorigenic tissue undergoing healing and/or inflammation. This has raised the question of whether these are distinct processes or the same process occuring under physiological versus pathological environments [6]. However, it is important to note that EMT in carcinogenesis refers to a transient and malleable cellular program which can be altered and reversed through activation of the mesenchymal-to-epithelial transition (MET), a process believed to be critical for colonization of metastatic sites [53]. Unlike tumorigenesis which occurs as a result of a cell-autologous insult (i.e. oncogenic mutations, tumor suppressor 


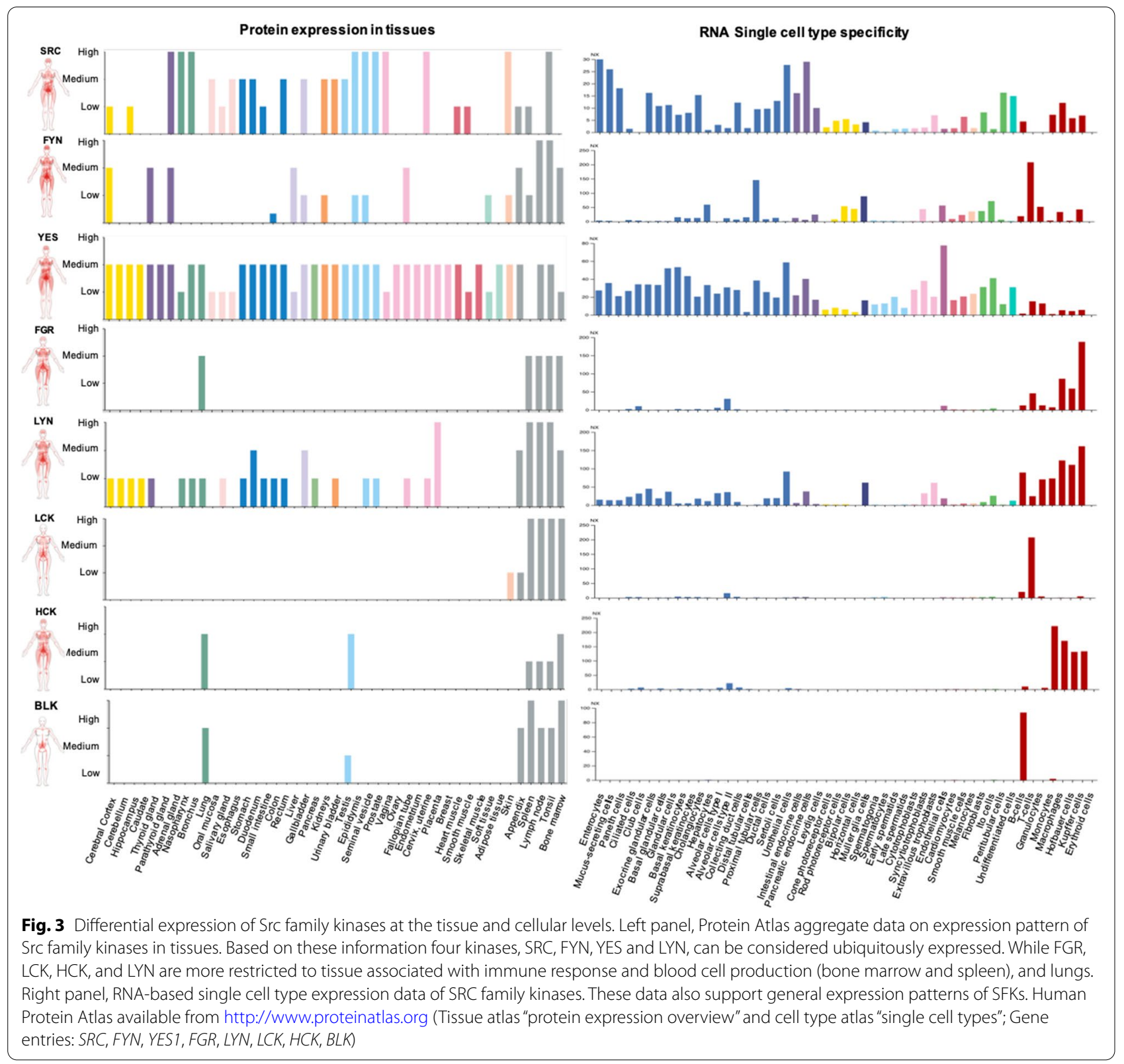

loss), EMT is an inducible process which results from a combination of epigenetic alterations and tumor-stromal interactions that lead to transcriptional reprogramming through activation of EMT transcription factors (EMTTFs) [6]. Hence, in the following sections, we will evaluate the role of SFKs in mediating the morphological, signaling, and transcriptional alterations associated with the EMT.

\section{SFKs and the actin cytoskeleton}

SFKs are key regulators of morphology and epithelial integrity through regulation of actin cytoskeletal dynamics and cellular adhesions. The EMT is characterized by morphological changes which occur as a result of disappearance of cell-cell junctions and actin-cytoskeleton rearrangement [50]. Changes in other cytoskeletal proteins like intermediate filaments also occur, with the most important one being a decrease in cytokeratin and upregulation of vimentin [54]. Early studies showed SRCinduced mitosis and morphological changes were driven by separate pathways; however, it was also noted that both required membrane localization [55]. Specifically, work by Frame et al., showed that SRC activity was spatiotemporally dependent: at earlier times upon activation 
oncogenic SRC (v-SRC) localized to the periphery predominantly to discrete adhesions and relocated to the membrane and residual adhesion at later times [55]. Changes in E-cadherin expression during the EMT are largely attributed to hypermethylation and transcriptional repression of the E-cadherin gene $(\mathrm{CDH1})$ mediated by EMT-TFs. Classical EMT transcription factors such as Snail and ZEB1 bind directly to the $C D H 1$ promoter and repress its transcription. Moreover, EMT-TFs have been shown ro recruit other transcriptional regulatory complexes to the $C D H 1$ promoter. For example, both SNAIL and ZEB1 repress E-cadherin expression through direct binding to the E-boxes in the $C D H 1$ promoter, with SNAIL recruiting the polycomb repressive complex [56-58], while ZEB1 recruits chromatin modifier complexes $[59,60]$. E-cadherin repression leads to cellular junction disassembly, loss of typical epithelial cobblestone morphology and acquisition of mesenchymal spindle-shaped morphology [6]. However, while the formation of new E-cadherin is repressed transcriptionally by EMT-TFs, E-cadherin present in cellular junctions needs to be destabilized in order for adherens junctions to disassemble. Early work by Behrens et al., linked SRC activation to increased E-cadherin/ $\beta$-catenin phosphorylation, loss of cell-cell contacts and acquisition of fibroblast-like morphology [61]. Thus, in the next sections we will discuss the role of SFKs in mediating key morphological and adhesion changes associated with the EMT, with a particular focus on those dependent on actin-cytoskeleton dynamics (Fig. 4).

\section{Changes in cell adhesion and polarity}

A key feature of the EMT is loss of cellular junctions such as adherens junction (AJ) and focal adhesions (FA).

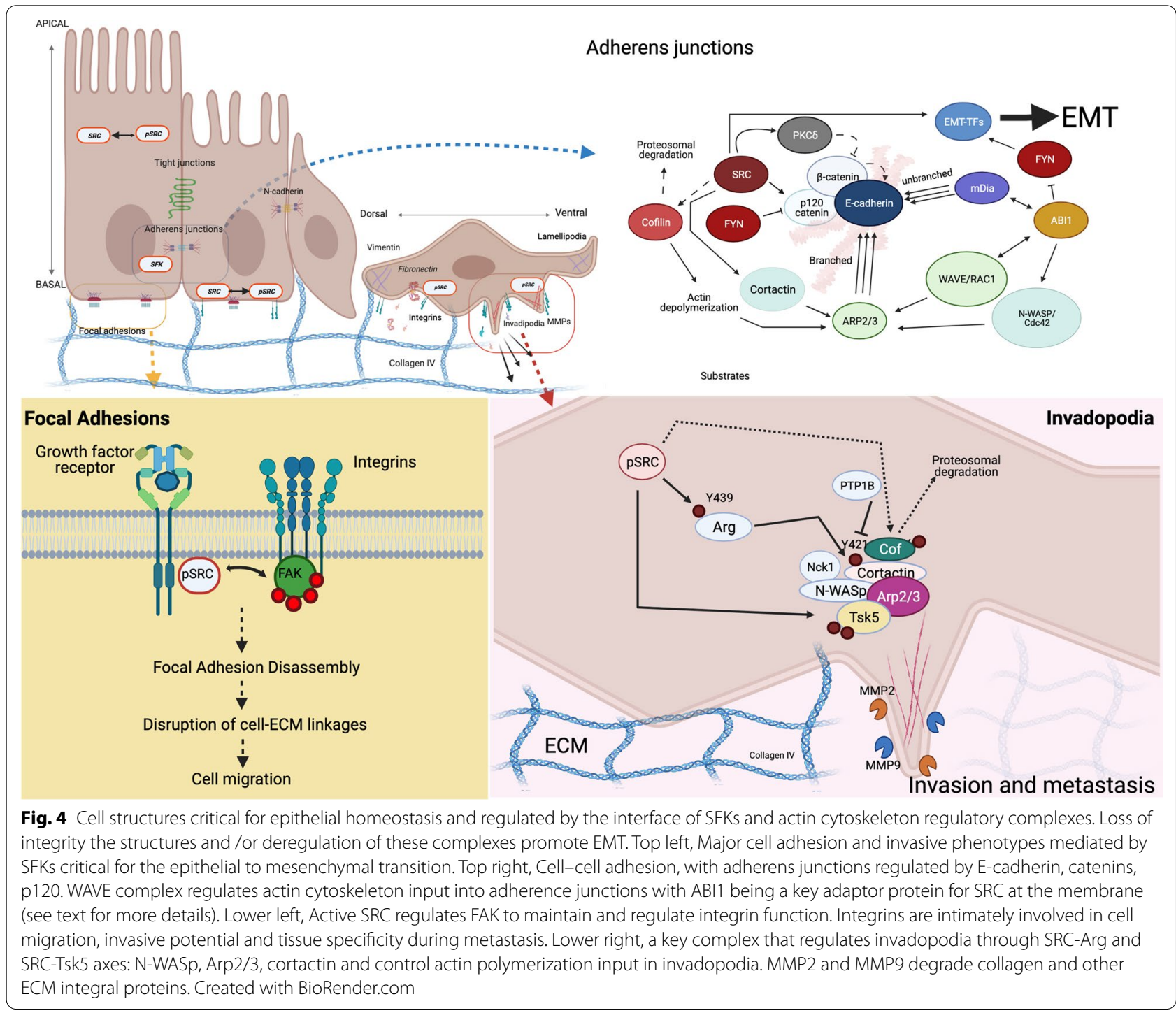


Adherens junctions link adjacent epithelial cells together, as such, they play a critical role in epithelial cell integrity, tissue formation and tumor suppression [62]. AJs consist of cadherin-based cellular junctions attached to the actin-cytoskeleton by catenin proteins. Briefly, E-cadherin is an adhesion molecule that forms homodimers with molecules on adjacent cells. On the other hand, catenins serve to stabilize cadherin-based junctions by linking them to the actin cytoskeleton. Specifically, p120-catenin binds to the cytoplasmic tail of E-cadherin and stabilizes it by inhibiting its endocytosis; $\beta$-catenin also binds to E-cadherin and recruits $\alpha$-catenin; then, $\alpha$-catenin binds to actin and recruits other important actin-binding proteins which together regulate junctional stability [63-66]. As such, regulatory complexes involved in actin-cytoskeleton dynamics play a critical role in the stabilization and formation of adherens junctions, many of which have been implicated with invasion and metastasis in a variety of different cancers [66].

The ARP2/3 complex is one of three known actinnucleators and it is unique in its ability to organize branched-actin filaments [67]. The most well characterized nucleation-promoting factors (NPF) known to activate ARP2/3 activity are Wiskott-Aldrich syndrome protein (WASP and neural (N)-WASP) and WAVE (WASP-family verprolin-homologous protein), which function downstream of small RHO family GTPases [67]. WAVE is a heteropentameric complex comprised of WAVE $1 / 2 / 3$, ABI1/2/3, CYFIP1/2, NAP $1 / 2$, and BRK1(HSPC300), which regulates ARP2/3-dependent actin dynamics through activation of the Rho family small GTPase, RAC1 [68]. Work by Takenawa and colleagues showed the essential role of the WAVE regulatory complex (WRC) in the formation and stabilization of AJs [68]. Interestingly, authors showed that depletion of the adaptor protein ABI1 or BRK1 had a more significant effect on cell-cell adhesion formation than did WAVE2 depletion, which was attributed to the redundancy between WAVE1 and WAVE2 proteins, as double knock-down of WAVE1/2 generated a more pronounced defect on cell-cell junction formation than either alone [68]. Later, it was shown that ABI1 was also involved in regulating unbranched actin-polymerization by a formindependent pathway through interactions with the Diaphanouse formin, mDia1 [69]. Moreover, ABI1 also binds to and activates N-WASP/Cdc42-dependent Arp2/3 activation [70]. Of note, in addition to its Abl-kinase regulatory role through pY213, previous work from our lab has shown ABI1-pY421 is a high affinity substrate for the SH2 domain of SFKs [71, 72]. More recently, we showed that ABI1 is a key EMT regulator through modulation of the WNT5a-FYN-STAT3 signaling axis in prostate cancer [73]. Combined, these findings show that ABI1 is a key connector of actin-cytoskeletal dynamics through the regulation of kinases and actin nucleation promoting factors (Fig. 4, Top right panel).

Work conducted by Chen and colleagues showed that SRC-mediated $\mathrm{PKC} \delta$-activation in response to growth factor stimulation led to increased phosphorylation of E-cadherin at Thr790, which decreased its binding affinity for $\beta$-catenin and promoted the dissociation of adherens junctions [74]. Castaño et al., showed the importance of SFK-mediated phosphorylation of p120catenin-induced Rho A activation. While FYN-mediated phosphorylation of Y112 inhibited p120-catenin interaction with Rho A, SRC-mediated phosphorylation of Y217 and Y228 promoted this interaction [75]. Moreover, Yoo et al., showed that v-SRC-mediated phosphorylation of cofilin at Y68 induced its ubiquitination and proteosomal degradation [76]. Cofilin is a key regulator of actindynamics and membrane protrusions by promoting actin-depolymerization, and generates preferred substrates for Arp2/3-mediated actin polymerization [77]. Hence, SFKs play a critical role in modulating the activity of both actin-polymerization and depolymerization at adherens junctions. This suggests that cellular junction stability is tighly regulated by the interplay between different SFKs.

In addition to disruption of cellular junctions, EMT activation induces changes in cell-polarity through disruption of tight junction protein complexes involved in cell polarity maintenance $[78,79]$. Typically, epithelial cells have apical-basal polarity, which gets converted to front-rear polarity in the mesenchymal state. Partitioning-defective (PAR) complexes (comprising PAR6, PAR3 and atypical protein kinase $\mathrm{C}(\mathrm{aPKC})$ and Crumbs complexes (comprising Crumbs (CRB), protein associated with Lin-7 1 (PALS1) and PALS1-associated tight junction protein (PATJ) localize apically in association with tight junctions and define the apical compartment. Scribble complexes (comprising Scribble (SCRIB), Discs large (DLG) and lethal giant larvae (LGL)) define the basolateral compartment. This is also accomplished through reorganization of the actin cytoskeleton. Combined, these morphological and polarity changes prepare the cell for acquisition of motility. SRC promotes cellular junction disassembly through activation of the focal adhesion kinase (FAK). Once activated, FAK promotes focal adhesion disassembly, disrupts cell-ECM linkages and initiates cell migration through regulation of integrin signaling [80].

\section{Invadopodia}

SRC has been shown to localize primarily to the membrane of invading tumors. Cells acquire invasive properties through formation of actin-based protrusions 
known as invadopodia along with secretion of matrix metalloproteinases (MMPs), which can degrade extracellular matrix (ECM) proteins [81]. Invadopodia are specialized membrane protrusions containing a primarily branched F-actin core and actin regulatory proteins, induced by growth factor or ECM signals [82, 83]. Many of these growth factor invadopodia-inducing pathways converge on key signal transducers like Rho family GTPases, phosphoinositide 3-kinase (PI3K) and SRC kinase [84, 85]. Work conducted by Artym et al., showed that there are two aspects to invadopodium, a structural and a functional component $[83,86]$.

The structural component recruits actin-regulatory complexes such as N-WASP, cortactin, Arp $2 / 3$, and dynamin [87]. Many essential components for invadopodia formation have been shown to interact with and/ or be phosphorylated by the prototypic SFK, c-Src. Cortactin is another important Arp2/3 nucleation promoting factor and is also a SRC-substrate [88]. Cortactin's activity promotes and stabilizes branched-actin filament formation by directly binding to the Arp $2 / 3$ actin-regulatory complex [89]. SRC-mediated phosphorylation of cortactin at Y421 enhanced actin assembly, and has been shown to be critical in mediating activation of the Nck-N-WASp complex, one of the earliest steps in invadopodia formation [83, 90, 91]. Furthermore, SRC-mediated phosphorylation of Tsk5, an adaptor protein essential for invadopodia formation, has been shown to regulate invadopodia-associated invasion in prostate cancer [92, 93].

As previously mentioned, the functional component of invadopodia utilizes matrix metalloproteases (MMPs), which are proteolytic enzymes that degrade the ECM [86]. Invadopodia have been shown to rely on membrane type 1 MMP (MT-MMP), MMP-type 2 (MMP-2) and MMP-9 for ECM degradation [94, 95]. MMP-2 and MMP-9 are particularly linked to invasion and metastasis as they are able to degrade collagen type-IV, a major component of the basement membrane [96]. Previous work conducted by Cortes-Reynosa and colleagues showed that MMP-9 secretion was mediated in a SRC and FAK-dependent manner [97]. Moreover, Eckert and colleagues showed that SRC, activated through TWIST1 transcription factor and platelet-derived Growth Factor Receptor (PDGFR $\alpha$ ), mediates formation of invadopodia to degrade ECM and promote cancer cell invasion. Treatment with selective SRC inhibitors reduced ECM degradation by fivefold [82]. Moreover, Abelson-interactor 1 (ABI1), a WAVE regulatory member and N-WASP regulator, has also been implicated in the regulation of invadopodia formation through regulation of the SRCId1-MMP9 axis [98]. All of these combined support SRC's critical role in invadopodia formation.

\section{SFK's role as signal transduction mediators} in EMT-inducing pathways

The classical EMT-TFs include the zinc-finger E-box binding homeobox factors ZEB1 and ZEB2, Snail (SNAI1), SLUG (SNAI2), and the basic helix-loop-helix factors TWIST1 and TWIST2 [99]. However, other transcription factors have been identified to be critical in the progression of EMT in different tumors [100, 101]. A feature which strengthens the robustness of the EMT once initiated is the positive feedback among EMT-TFs. For example, SNAIL enhances WNT signaling by improving the transcriptional activity of $\beta$-catenin via direct interactions in the nucleus and by increasing responsiveness to WNT signaling. As a transcriptional cofactor, $\beta$-catenin binds to the promoter region of other EMT-TFs and induces their expression $(102,103)$. This reinforces the idea that EMT in carcinogenesis results from an interplay between driver-mutations and hijacking of developmental pathways which allows cancer cells to overcome extrinsic insults (e.g. host-immunity, anti-cancer therapeutics), invade and metastasize. SFKs have no intrinsic transcriptional activity, however, they have been shown to directly phosphorylate and activate the transcriptional activity of EMT-inducing transcription factors such as the androgen receptor (AR) and the signal transducer and activator of transcription 3 (STAT3) [73, 104-106]. This emphasizes that while EMT-TFs are critical in maintaining global cellular changes through regulation of gene expression, alterations in signaling pathways are responsible for inducing and executing these changes. SFKs have been shown to be critical in a variety of signaling transduction pathways, known to regulate the EMT, in which they serve as both inducers and connectors. Moreover, dysregulated signaling pathways may be the cause for the partial-EMT observed in cancer which results in tumor cells displaying characteristics that fall under a spectrum of epithelial and mesenchymal features rather than a fully differentiated state. Thus in the following sections we will evaluate the roles of SFKs in modulating activity of some key EMT-inducing pathways. Specifically, TGF- $\beta /$ SMAD, Wnt, NOTCH and EGFR signaling (Fig. 5).

\section{TGF- $\beta$ pathway}

TGF- $\beta$ signaling has been heavily linked to the activation of EMT and cancer stem cell (CSC) generation. TGF- $\beta$ lingands bind to complexes of TGF- $\beta$ receptor Type 1 (TGF $\beta R 1$ ) and TGF $\beta R 2$, leading to the phosphorylation of SMAD2/3, which proceed to form heteromeric complexes with SMAD4. Similarly, engagement of bone morphogenic proteins (BMPs) lead to activation of SMAD1/5, which can also complex with SMAD4. Once these SMAD trimeric complexes migrate to the nucleus, they activate transcription of mesenchymal genes. TGF- $\beta$ 


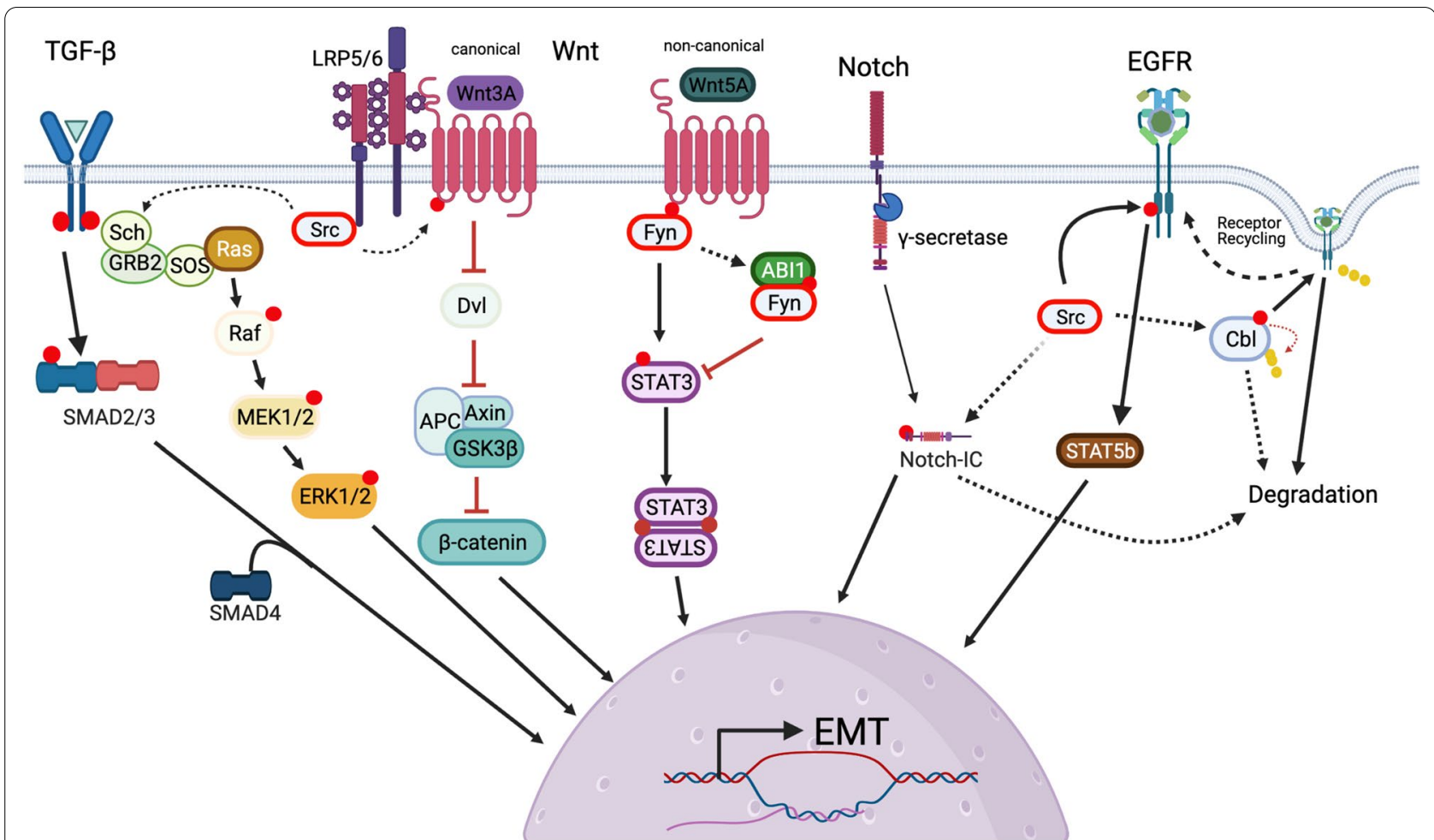

Fig. 5 Cell signals that regulate SFKs input into major cellular pathways. Roles of SFKs in modulating some of the key EMT-inducing pathways. Top, Signals initiated by a variety of receptors, TGF-beta, WNT pathway receptors (LRP5/6), Notch and growth factor receptors such as EGFR. All signals involve cytoplasmic regulators and modulators which end up activating transcription factors/coactivators to regulate gene expression. See text for details. Created with BioRender.com

signaling induces the formation of myofibroblasts that secrete significantly higher levels of TGF- $\beta$ which helps induce and/or maintain EMT in adjacent carcinoma cells. In addition to signaling through cytokine and growth factors, cancer associated fibroblasts can alter methylation patterns in EMT-regulating genes and induce mesenchymal features and CSC-like properties. Shipitsin et al., showed that there is an increase in TFG $\beta-1$ and TF $\beta$ II in CSC when compared to more differentiated controls. Additionally, inhibition of TGF- $\beta$ signaling led to acquisition of a more epithelial phenotype [107].

Multiple studies support the role of SRC in inducing the transition of TGF $\beta$ signaling from tumor suppressive to oncogenic. Work by Galliher et al., identified the role of the $\alpha v \beta 3 / \mathrm{SRC} / \mathrm{T} \beta \mathrm{RII}$ signaling axis in promoting the oncogenic signaling of TFG- $\beta$. Specifically, $\beta 3$ interacts with TGF $\beta$ R2 which allows SRC to phosphorylate T $\beta R$-II on Y284, generating a docking site for the SH2 domains of Grb2 and Shc. Abrogation of this phosphorylation site in T $\beta R$-II did not affect SMAD2/3 activation but completely prevented p38 MAPK activation [108]. More recently, Zhang et al. showed that TGF- $\beta$ induces SRC activation through a SMAD-independent, NADPH-oxidase dependent manner [109]. Specifically,
TGF- $\beta$ induces a transient increase in extracellular $\mathrm{H} 2 \mathrm{O} 2$ leading to SRC activation in a redox-dependent manner which is mediated by cysteines 248, 277, 490 and 501 [109]. Moreover, Work by Park et al., showed that TGF$\beta$-induced apoptosis is SRC-dependent. In TGF- $\beta 1$ sensitive cells, TGF- $\beta 1$ induces transient activation of SRC and its subsequent caspase-mediated degradation and cell death. Moreover, SRC-activation led to inhibition of apoptosis through promoting the activation of pro-apoptotic enzymes JNK, p38 and caspases [110].

\section{WNT signaling}

SFK activity is also important in the signal transduction of Wnt signaling pathways. Both canonical ( $\beta$-catenindependent) and non-canonical ( $\beta$-catenin independent) signaling pathways have been shown to play critical roles in the EMT in various tumors [111]. In canonical Wnt signaling, $\beta$-catenin acts as a transcriptional cofactor and its nuclear translocation upon ligand-receptor binding activates transcription of genes involved in proliferation, tumorigenesis, cell fate specification and differentiation [112]. In addition, $\beta$-catenin is a critical structural protein involved in cell-cell junctions, as previously discussed. $\beta$-catenin forms a complex with 
cadherins to maintain cell-cell contacts and the loss of this interactions leads to the disassembly of adherens junctions [113]. Therefore, E-cadherin is a negative regulator of the canonical Wnt pathway through sequestering of $\beta$-catenin, as all of the $\beta$-catenin available in an epithelial cell is used in the formation of adherens junctions. Activation of EMT leads to disintegration of cell-cell junctions and subsequent release of $\beta$-catenin, which transduces Wnt signaling by entering the nucleus and stimulating transcription through an association with T-cell factor (TCF) and Lymphocyte enhancerbinding factor (LEF) [114].The interaction between $\beta$-catenin and E-cadherin can be disrupted by phosphorylation of tyrosine $\mathrm{Y} 654$ on $\beta$-catenin, as this tyrosine is located at the site which mediates their interaction $[113,115]$. In development, this interaction has been reported to be repressed during mesoderm invagination. Brunet and colleagues showed that SRC homolog, SRC42A, phosphorylates Y654 on $\beta$-catenin, which results in an increase of $\beta$-catenin in the cytoplasm and subsequent nuclear translocation [115]. The repression of SRC activity by PP2, a SRC inhibitor, resulted in the maintenance of E-cadherin/ $\beta$-catenin interaction [115]. Moreover, SRC overexpression has been implicated in regulating protein synthesis of $\beta$-catenin through a Cap-dependent mechanism [116]. Specifically, SRC enhances protein synthesis through phosphorylation of the translation initiation factors elF4E and its inhibitors elF4E-BP1 through the PI3K-mTOR and Erk-MAPK pathways [116].

In vitro studies in HER2-positive breast cancer cells showed that stimulation with recombinant WNT3A, a canonical ligand, induced expression of TWIST, SLUG and $\mathrm{N}$-cadherin and repressed the expression of E-cadherin [117]. Thus, increased Wnt ligand availability promotes EMT activation and malignant progression [118-120]. Additionally, work by Gujral et al., identified an upregulation of non-canonical Wnt ligands (WNT5a and WNT5b) and their cognate receptor Frizzled2 (FZD2) in late-stage metastatic carcinomas of different origins which correlated with an increase in EMT markers and worst patient outcomes. Their work identified the WNT5a-FYN-STAT3 signaling axis as the main driver of Wnt5a-mediated cell migration and EMT [121]. Studies from our lab identified Abelsoninteractor 1 (ABI1), adaptor and scaffold protein, as an EMT regulator through modulation of the Wnt5a-FYNSTAT3 axis and the WAVE regulatory complex [73]. Recent work by Villarroel and colleagues demonstrated both canonical (WNT3a) and non-canonical (WNT5a) ligands lead to activation of FYN and STAT3-mediated EMT [122]. Interestingly, ABI1 has been shown to regulate SRC kinase activity, and prevent SRC-mediated breast cancer progression [98].

\section{NOTCH1 signaling}

Mutliple studies have shown the link between Notch signaling and activation of the EMT through induction of SNAIL and SLUG expression in normal and pathological conditions [123-127]. Canonical Notch signaling is a type of juxtacrine cell communication, mediated by a 'donor' or 'secretory' cell and an "acceptor" or "receiver" cell [128]. Notch-1 signaling is mainly involved in controlling cell fate decisions, differentiation and proliferation. There are four isoforms of Notch [1-4] which bind to and are activated by Delta-like (DLL1, DLL3, and DLL4) or Jagged family (Jag1 and Jag2) of ligands. This binding triggers a series of proteolytic cleavage events that lead to the generation of the active, intracellular fragment of NOTCH (NICD). Notch-ICD translocates to the nucleus and associates with transcriptional activators to induce expression of target genes. Interestingly, a recent study by LaFoya and colleagues showed that SRC phosphorylates the intracellular domain of Notch at Y2074 and Y2145, which decreases NICD binding to its co-transcriptional activator Mastermind-like (MAML), impeding its transcriptional activity [128]. This suggests that in the context of NOTCH-signaling, SRC may serve as an EMT repressor.

\section{EGFR signaling}

The epidermal growth factor receptor (EGFR) family is a subclass of the receptor tyrosine kinase super family that is comprises of four members: ERBB1 (EGFR), ERBB2 (HER2), ERBB3 (HER3) and ERBB4 (HER4) [129]. All EGFR family members are transmembrane glycoprotein composed of an extracellular ligand-binding domain, a hydrophobic transmembrane region, an intracellular receptor tyrosine kinase (RTK) domain, and a C-terminal cytoplasmic tail [130]. EGFR members are ubiquitously expressed in various types of tissues including epithelial, mesenchymal and neuronal origin [129]. EGFR signal cascade is initiated through ligand-induced receptor dimerization which leads to activation of intrinsic tyrosine kinase (TK) domain and autophosphorylation of the cytoplasmic tail [131, 132]. Once phosphorylated, the cytoplasmic tail serve as a docking sites to recruits cellular kinases, or signal adaptor proteins for downstream signal transduction [131, 133]. Upon activation, EGFR signaling is involved in multiple cellular events like cytoskeleton dynamics reorganization and transcriptional reprograming which promote cellular activities that are critical for both maintenance of normal cell functions and malignant progression [131]. These cellular 
activities include proliferation, division, migration, and adhesion formation, which are determined through the specificity of different EGFR-binding ligands and the combination of EGFR dimers into homo- or heterodimers [134-141]. Enhanced EGFR signaling is often found in multi-types of epithelial oncogenic events due to overexpression or mutations of EGFR receptors, and autocrine or paracrine production of EGF family ligands [129].

In tumors, EGFR receptors have been shown to work synergistically in coordination with SRC and other tyrosine kinases, promoting tumor progression. Studies have indicated that EGFR receptors and c-SRC were co-overexpressed in $70 \%$ of breast tumors and were shown to work together to promote tumor growth in a mice xenograft study [142]. Moreover, the presence of SRC was indicated to be necessary for EGFR2-mediated anchorage-independent growth, cell motility regulation and cell survival [143-145]. The molecular mechanism of SRC/ EGFR interactions have been revealed by multiple studies where SRC was shown to be associated with activated EGFR receptors, most likely via an $\mathrm{SH} 2$ /phospho-tyrosine interaction. This leads to SRC activation, promoting the phosphorylation of its substrates [144, 146, 147]. SRC phosphorylates EGFR at Y845, which has been shown to be important for EGF-induced proliferation and survival through STAT5b and Cox II, respectively [145]. Moreover, SRC can be activated by other signaling cascades like G-protein coupled receptors (GPCRs) to promote phosphorylation of multiple tyrosine sites of EGFR receptors, including Tyr 845 [148-150]. Other studies have indicated that through phosphorylation of clathrin and dynamin, SRC modulates the internalization of EGFRs to enhance the endosomal pool of activated receptors [151, 152]. SRC interacts with EGFR to promote degradation of $\mathrm{Cbl}$, a E3 ubiquitin-protein ligase, by SRC-mediated Cbl phosphorylation, which protects EGFR receptors from $\mathrm{Cbl}$ mediated ubiquitination and degradation, allowing for receptor recycling [153]. Due to the critical oncogenic roles of EGFR signaling, various EGFR tyrosine kinase inhibitors (TKI) have been developed to abrogate EGFR signaling by competing with ligand binding or the ATP binding pocket on the catalytic domain [130]. However, treatment resistance emerges due to secondary EGFR mutations and/or activation of alternative pathways [154-156].

\section{SFK's role in mediating treatment resistance in targeted-therapies}

Metastatic disease accounts for over $90 \%$ of cancerrelated deaths which underscores the importance in understanding key cellular pathways involved in mediating treatment resistance [157, 158]. Both SFKs and
EMT activation have been identified as key mediators of treatment resistance to a variety of different anti-cancer therapies [159-161]. Concurrent pan-SRC inhibition has been shown to restore sensitivity to a variety of therapies which underscores the importance of SFK in mediating treatment resistance [162-165]. However, while preclinical studies have suggested great promise in the use of SFK-inhibitors, their clinical outcomes have left much to be desired. Therefore, in this segment we will evaluate mechanisms through which SFKs have been implicated in mediating treatment resistance and its implications in the treatment of metastatic disease. To generate a more thorough review, we will focus on treatments targeting the previously mentioned pathways for which SFK activity is of critical importance (see "Src family kinases in the epithelial mesenchymal transition (EMT)" section).

\section{SFK's role in mediating treatment resistance in targeted-therapies}

In breast cancer, SRC activation is associated with overexpression of P-cadherin and stem cell-like phenotype that promotes cell invasion and tumorigenesis. SRC inhibition by dasatinib disrupts P-cadherin downstream signaling, rescues cell membrane E-cadherin/p120-catenin complex and recovers cell-cell adhesion properties [166]. Several studies have addressed the interactions and cross-talks among SRC, ER and AR signaling pathways. SRC activation is observed in $\sim 40 \%$ of $E R+$ breast cancer and synergistic interaction between EGFR, ER and SRC facilitates hormone receptor signaling and confers resistance to endocrine therapies [167]. Moreover, SRC activation has been shown to contribute to tamoxifen resistance in pre-clinical models and is associated with a poor patient response to tamoxifen clinically [168]. Later work by Vallabhaneni and colleagues showed that in the context of proline, glutamic acid, leucine-rich protein 1 (PELP1), an ER $\alpha$ co-regulator and proto-oncogene, SRC inhibition could overcome endocrine resistance [169]. A different study suggests that LYN activity could mediate anti-estrogen therapy resistance in estrogen receptorpositive $(\mathrm{ER}(+))$ breast cancers [170]. Work by Elias, et al., in breast cancer also identified FYN as an important molecule in tamoxifen resistance [171]. Specifically, their study suggested that through phosphorylation of cell cycle proteins such as Cdc25A, FYN was helping to overcome the anti-proliferative effects of tamoxifen [171]. However, it is still not clear how different members of SFK family are involved in cancer progression and how distinct SFKs-dependent molecular mechanisms regulate tumorigenic pathways in different cancer types. Tabaries et al. bring attention to the opposing roles of different SFK family members in breast cancer and advocate for the use of selective inhibitors in clinical practice. Their 
study shows that Claudin 2-dependent breast cancer metastasis is differentially regulated by different SFKs. Their in vivo studies showed loss of YES or FYN induces Claudin-2 expression; whereas, diminishing LYN levels impairs Claudin-2 expression and reduces breast cancer metastasis [172]. Pro-metastatic activity of LYN has also been suggested in Ewing's sarcoma by a study showing a significantly decreased tumor invasive capacity in cell culture when LYN was inhibited by small interfering RNA [173].

Another class of targeted therapy which has played a critical role in the treatment of metastatic breast cancer is receptor tyrosine kinase inhibitors such as trastuzumab, which targets the human epidermal growth factor receptor 2 (HER2). However, resistance to therapy is common and SRC activation has been linked to resistance to antiHER2 therapy [174]. HER2 associates with SRC and promotes SRC activation through promoting its synthesis and stability. One of the important anti-tumor mechanisms of trastuzumab is inhibition of HER2-mediated SRC activation, thus SRC remains inactive and unable to inhibit phosphatase and tensin homolog (PTEN), leading to its reactivation as a functional tumor suppressor. However, SRC signaling is often upregulated in breast tumors as a result of many different upstream dysregulations (i.e. RTK re-programming and PTEN loss) and does not require HER2 for activation. This leads to resistance to anti-HER2 therapy in a SRC-dependent manner $[175,176]$. Another mechanism of SRC-mediated trastuzumab-resistance was reported by Liang and colleagues which involves EpoR, a receptor co-expressed with HER2 in breast cancer cells. Ligand-engagement of the EpoR leads to JAK2-mediated SRC activation [177]. Moreover, TGF $\beta$ integrates HER2 receptor and integrin signaling leading to SRC-FAK pathway activation and trastuzumab resistance [178]. In addition to trastuzumab, acquiredresistance to other RTK-targeted therapies (i.e. lapatinib) have been reported to involve SRC hyperactivation [176]. Convergence of these resistance mechanisms on SRC led to studies by Zhang et al., which showed addition of a SRC inhibitor to trastuzumab-resistant breast cancer cell lines restored sensitivity to trastuzumab therapy in vivo [174].

Similar to breast tissue, prostate tissue is responsive and dependent on hormonal-stimulation for growthspecifically it is dependent on androgens. The androgen receptor (AR) is a nuclear hormone receptor that regulates gene expression of proteins involved in cell proliferation and tumor growth. AR signaling is commonly upregulated in prostate cancer and has been associated with inducing EMT [179]. Guo and colleagues found that there was an elevated tyrosine phosphorylation at Y534 of AR in hormone refractory tumor samples, associated with increased nuclear translocation and transcription factor activity in androgen depleted conditions [106]. Work by Whang and colleagues found that SRCmediated phosphorylation of AR at tyrosine Y534 could promote androgen independent growth in hormone dependent cell lines $[105,180]$. Together these data suggests that SRC-mediated phosphorylation of the AR plays a role in mediating cancer progression and development of treatment resistance. Furthermore, genomic profiling studies of prostate cancer cell lines demonstrated an inverse correlation between SRC activity and androgen signaling, implying that SRC activity plays a role in endocrine resistant prostate tumors which was shown to be overcome with SRC inhibition [181]. Moreover, in a phase-II study dasatinib monotherapy, a pan-SFK inhibitor, seemed promising for the treatment of chemotherapy-naïve, metastatic castration-resistant prostate cancer (mCRPC) with bone metastasis [182]. However, its efficacy was diminished when used for treatment of mCRPC in patients who had undergone prior chemotherapy regimens [183].

SRC-mediated resistance to RTK-targeted therapies has also been observed with anti-EGFR therapies. EGFR and SRC activities are elevated in the majority of the lung, colorectal and pancreatic tumors. EGFR interacts with SRC, and the transformation capability of two EGFR catalytic domain mutants has been shown to be dependent on SRC [156]. SRC activation enhances EGFR activation and downstream PI3K/Akt signaling, thus SRC has been suggested to mediate cetuximab resistance through facilitating nuclear translocation of EGFR. The combination of dasatinib with erlotinib, an EGFR inhibitor, showed more promising results with inhibition of angiogenesis and eliciting disease control in $63 \%$ of patients [184]. In the analysis of combined erotinib, dasatinib treatment of patients with head and neck squamous cell carcinoma (HNSCC), it has been suggested that basal expression of pSTAT3 may be independent of SRC and explain therapeutic resistance to dasatinib [185]. Dasatinib in combination with cetuximab, an EGF inhibitor, has been demonstrated to be safe and has a potential to overcome cetuximab resistance in solid tumors [186, 187]. Furthermore, a study by Weng et al., showed the mesenchymal phenotypes of TKI-resistant cells, suggesting the EMT contributes to the acquired resistance of EGFR TKI treatments [188]. In this study, authors showed the constitutive activation of EGFR signaling in TKI-resistance cells renders EMT features in cells through activation of the SRC/Hakai axis, which mediates E-cadherin ubiquitination and degradation $[188,189]$. They further indicated that the inhibition of SRC/Hakai axis reversed EMT phenotypes by stabilizing cellular E-cadherin levels, which increases the sensitivity to TKI in TKI-resistance cells. This underscores the 
importance of SRC-mediated EMT processes in inducing treatment resistance of targeted therapies.

\section{Lessons learned from Src inhibitors}

Despite large preclinical data that demonstrated therapeutic promise of SFK inhibition in different tumors, so far there have not been much success demonstrated in clinical trials using SFK inhibitors as monotherapy. Current FDA-approved SFK inhibitors include bosutinib, dasatinib, and ponatinib for the treatment of chronic myelogenous leukemia and vandetanib for the treatment of medullary thyroid cancer. However, these inhibitors lack specificity among SFK members and they are known to inhibit other tyrosine kinases [9]. Dasatinib monotherapy did not appear to be promising in patients with metastatic non-small cell lung carcinoma (NSCLC) with clinical activity lower than what is generally observed in patients who receive chemotherapy [190, 191]. Moreover, limited single-agent activity with dasatinib was also observed in patients with advanced $\mathrm{HR}+$ breast cancer [192]. The SrRC and BCR-Abl inhibitors saracatinib and AZD0424 that showed promise in pre-clinical studies also have not demonstrated expected efficacy in patients. In relapse clear cell renal cell carcinoma, advanced pancreatic adenocarcinoma, and ovarian, fallopian-tube and peritoneal cancer, addition of Saracatinib did not increase the efficacy of standard therapy [193-195]. AZD0424 displayed no evidence of efficacy as monotherapy despite a clear pharmacodynamic effect [196]. However, it is important to consider that activation of alternative oncogenic pathways which lead to diminish SRC signaling may render resistance to SRC inhibitors. For example, the status of the von Hippel-Linday (VHL) gene in renal cell carcinoma dictates sensitivity to SRC inhibition through the HIF-regulated VHL-PTP1B-SRC signaling axis [197]. Moreover, studies by Matrone and colleagues showed that SRC inhibition leads to promotion of microtentacle formation, a microtubule-based protrusion involved in capillary retention of circulating tumor cells to distant organ sites [198]. This suggests monotherapy with SFKinhibitors may promote rather than inhibit metastatic disease. This underscores the importance of developing SFK-inhibitors with higher specificity, as lack of selectivity may select for more invasive malignancies.

It has been suggested that the efficacy of clinical trials has been complicated by the patient population, with heavily penetrated tumors resistant to previous therapies and as well as by the absence of definite biomarkers that could suggest therapeutic effectiveness [199, 200]. The lack of definitive biomarkers was previously addressed by Arcaroli and colleagues, whose work showed that SRC pathway activation was a good indicator of sensitivity to SRC inhibition [201]. However, this has not been implemented in the design of clinical trials accessing the efficacy of SFK inhibitors in metastatic disease.

The synthetic lethality approaches that are now being used more and more in the treatment of cancer could be applied to the issue of complementation of SFK in signaling and where FYN and YES, for example, are upregulated in response to decreased SRC activity. As previously discussed, SFKs function as key connectors of proliferation and survival pathways and often serve to promote resistance to a variety of targeted therapies. Therefore, in addition to currently available inhibitors which target the kinase activity of SFKs, it would be imperative to develop $\mathrm{SH} 2$ or $\mathrm{SH} 3$ inhibitors which target protein interactions of SFKs with the goal to minimize compensation and crosstalk between signaling pathways. These type of inhibitors could potentially decrease acquire-treatment resistance due to activation of alternative pathways mediated by SFK activation.

\section{Conclusion}

SFK's role in invasion, metastasis, angiogenesis, tumormicroenvironment, immune-modulation and many other cellular processes makes it clear that while SFKdysregulation may not always lead to activation of EMT, EMT requires SFK activity for execution. Metastatic carcinomas are challenging to treat due to their ability to activate rapidly evolving programs which renders them adaptable to intrinsic and extrinsic insults such as the tumor microenvironment and anti-cancer treatments. Partial responses to treatments generate a race between host stromal and carcinoma cells, in which natural selection takes its course. Only those carcinoma cells "welladapted enough" to the new TME will survive, proliferate and continue to invade and metastasize. It is thus critical to evaluate the molecular changes induced by single and combination therapies on the cellular pathways, to assess for alterations which may serve as prognostic markers and/or therapeuric targets. As reviewed here, we see that members of the Src protein family share many similarities, however, there are key differences which could be utilized to magnify their individuality and generate inhibitors with higher specificity. As key connectors of signal transduction SFK activity is altered through many pathways such as those involved in intracellular, intercellular, and cell-ECM interactions without the need for alteration in total protein expression nor function. Moreover, it is clear that while EMT-TFs are detailing out the plan, SFKs belong to the front-line fighters which execute these plan. Therefore, it is imperative to continue to evaluate the role of individual SFKs in metastatic progression to be able to address the much needed clinical need for treatments of metastatic disease. 


\section{Abbreviations}

ABI1: Abelson interactor 1; AJ: Adherens junctions; AR: Androgen receptor; ARP2/3: Actin-related protein 2/3; ATP: Adenosine triphosphate; BLK: B lymphoid tyrosine kinase; BRK1: Breast tumor kinase; CRB: Crumbs; CSC Cancer stem cells; CYFIP: Cytoplasmic FMRP Interacting Protein 1; DLG: DisCS large; DLL: Delta-like ligand; EGFR: Epidermal growth factor receptor; EMT: Epithelial to mesenchymal transition; EMT-TFs: EMT transcription factors; EpoR: Erythropoietin Receptor; ER: Estrogen receptor; FA: Focal adhesion; FAK: Focal adhesion kinase; FDA: Food drug administration; FGR: Feline sarcoma viral protein Gardner-Rasheed; FZD2: Frizzled2; HCK: Hemopoietic cell kinase; HER: Human epithelial receptor; HIF: Hypoxia inducible factor; HR: Hormone receptor; IDRs: Intrinsically disordered regions; JAK2: Janus kinase 2; JNK: C-Jun N-terminal kinase; LCK: Lymphocyte cell-specific protein tyrosine kinase; LEF: Lymphocyte enhancer-binding factor; LGL: Lethal giant larvae; LYN: Lck-related novel protein tyrosine kinase; MAML: Mastermind-like; MAPK: Mitogen activated protein kinase; MET: Mesenchymal to epithelial transition; MMP: Matrix metalloproteinases; mTOR: Mammalian target of rapamycin; N-WASP: Neural Wiskott-Aldrich Syndrome protein; NADPH: Nicotinamide adenine dinucleotide phosphate; NAP: Nucleosome assembly protein; NICD: Intracellular fragment of NOTCH; NMDARs: N-methyl D-aspartate receptors; NOTCH: Notch homolog 1; NPF: Nucleation-promoting factors; NSCLC: Non-small cell lung carcinoma; PALS1: Protein-associated with Lin-7 1; PAR: Partitioning-defective; PCK: Protein kinase C; PDGFR: Platelet-derived growth factor receptor; PI3K: Phosphoinositide 3-kinase; PSD: Post-synaptic densities; PTP1B: Protein tyrosine phosphatase 1B; RTK: Receptor tyrosine kinase; SCRIB: Scribble; SFK: Src family kinases; SH: Src homology; Shp1/2: Src homology region 2 domain-containing phosphatase-1/2; SLUG (SNAI2): Snail homolog 2 of drosophila; SMAD: An acronym from the fusion of Caenorhabditis elegans Sma genes and the Drosophila Mad, Mothers against decapentaplegic; SNAIL: Snail homolog 1 of drosophila; SRC: Sarcoma; STAT: Signal transducer and activator of transcription; TCF: T-cell factor; TGF- $\beta$ : Transforming growth factor beta; TIMP2: Tissue inhibitor of metalloproteinases 2; TK: Tyrosine kinase; TKl: Tyrosine kinase inhibitors; TWIST: Twist homolog 1 of drosophila; UD: Unique domain; ULBR: Unique lipid binding region; V-SRC: Viral avian SRC; VHL: Von Hippel-Linday (VHL); WASP: Wiskott-Aldrich syndrome protein; WAVE: WASPfamily verprolin-homologous protein; WNT: Wingless/integrated; WRC: WAVE regulatory complex; ZEB: Zinc finger E-box binding homeobox.

\section{Acknowledgements}

We would like to thank Dr. Marius Sudol for his insightful suggestions and discussions in contribution towards this manuscript. We acknowledge the many scientist in the field who have contributied to the knowledge of Src family kinases in EMT and apologize for any unintentional omission due to space or scope limitations.

\section{Authors' contributions}

$\mathrm{MAO}$ and $\mathrm{LK}$ provided the concept for the review and designed all figures. $M A O$ wrote the review with input on selected sections from $T M, B P$, and $X L$. AB wrote the section on structural regulation of SFKs. LK wrote all figure legends and edited the paper. All correspondence should be addressed to Leszek Kotula. All authors read and approved the final manuscript.

\section{Funding}

This work was supported by grants from the National Cancer Institute R01CA161018 (LK), Carol Baldwin Breast Cancer Center Fund (LK), Al Todeshini Pancreatic Fund (LK), and Cancer Center Pilot Grant (LK).

\section{Availability of data and materials}

Not Applicable.

\section{Declarations}

Ethics approval and consent to participate Not Applicable.

\section{Consent for publication}

All authors provided consent for publication.

\section{Competing interests}

The authors declare that they have no competing interests.

\section{Author details}

${ }^{1}$ Department of Biochemistry and Molecular Biology, SUNY Upstate Medical University, Syracuse, USA. ${ }^{2}$ Department of Urology, SUNY Upstate Medical University, Syracuse, USA.

Received: 12 March 2021 Accepted: 14 May 2021

Published online: 30 June 2021

\section{References}

1. Rous P. A sarcoma of the fowl transmissible by an agent separable from the tumor cells. J Exp Med. 1911;13(4):397-411.

2. Oppermann $H$, Levinson AD, Varmus HE, Levintow L, Bishop JM. Uninfected vertebrate cells contain a protein that is closely related to the product of the avian sarcoma virus transforming gene (src). Proc Natl Acad Sci USA. 1979;76(4):1804-8.

3. Talamonti MS, Roh MS, Curley SA, Gallick GE. Increase in activity and level of pp60c-src in progressive stages of human colorectal cancer. J Clin Invest. 1993;91(1):53-60.

4. Thiery JP, Acloque H, Huang RY, Nieto MA. Epithelial-mesenchymal transitions in development and disease. Cell. 2009;139(5):871-90.

5. Saitoh M. Involvement of partial EMT in cancer progression. J Biochem. 2018;164(4):257-64.

6. Dongre A, Weinberg RA. New insights into the mechanisms of epithelial-mesenchymal transition and implications for cancer. Nat Rev Mol Cell Biol. 2019;20(2):69-84.

7. Patel A, Sabbineni H, Clarke A, Somanath PR. Novel roles of Src in cancer cell epithelial-to-mesenchymal transition, vascular permeability, microinvasion and metastasis. Life Sci. 2016;157:52-61.

8. Amata I, Maffei M, Pons M. Phosphorylation of unique domains of Src family kinases. Front Genet. 2014;5:181.

9. Roskoski R Jr. Src protein-tyrosine kinase structure, mechanism, and small molecule inhibitors. Pharmacol Res. 2015;94:9-25.

10. Serfas MS, Tyner AL. Brk, Srm, Frk, and Src42A form a distinct family of intracellular Src-like tyrosine kinases. Oncol Res. 2003;13(6-10):409-19.

11. McClendon CJ, Miller WT. Structure, function, and regulation of the SRMS tyrosine kinase. Int J Mol Sci. 2020;21(12).

12. Flesh MD. Myristylation and palmitylation of Src family members: the fats of the matter. Cell. 1994;76:411-3.

13. Sudol M, Greulich H, Newman L, Sarkar A, Sukegawa J, Yamamoto T. A novel Yes-related kinase, Yrk, is expressed at elevated levels in neural and hematopoietic tissues. Oncogene. 1993;8(4):823-31.

14. Carrera AC, Paradis H, Borlado LR, Roberts TM, Martinez C. Lck unique domain influences Lck specificity and biological function. J Biol Chem. 1995;270(7):3385-91.

15. Shaw AS, Amrein KE, Hammond C, Stern DF, Sefton BM, Rose JK. The Ick tyrosine protein kinase interacts with the cytoplasmic tail of the CD4 glycoprotein through its unique amino-terminal domain. Cell. 1989;59(4):627-36.

16. Perez Y, Maffei M, Igea A, Amata I, Gairi M, Nebreda AR, et al. Lipid binding by the Unique and $\mathrm{SH} 3$ domains of $\mathrm{c}$-Src suggests a new regulatory mechanism. Sci Rep. 2013;3:1295.

17. Perez Y, Gairi M, Pons M, Bernado P. Structural characterization of the natively unfolded $\mathrm{N}$-terminal domain of human c-Src kinase: insights into the role of phosphorylation of the unique domain. J Mol Biol. 2009;391(1):136-48

18. Amata I, Maffei M, Igea A, Gay M, Vilaseca M, Nebreda AR, et al. Multiphosphorylation of the intrinsically disordered unique domain of c-Src studied by in-cell and real-time NMR spectroscopy. ChemBioChem. 2013;14(14):1820-7.

19. Werdich $X Q$, Penn JS. Src, Fyn and Yes play differential roles in VEGFmediated endothelial cell events. Angiogenesis. 2005;8(4):315-26.

20. Summy JM, Qian Y, Jiang BH, Guappone-Koay A, Gatesman A, Shi X, et al. The SH4-Unique-SH3-SH2 domains dictate specificity in signaling that differentiate c-Yes from c-Src. J Cell Sci. 2003;116(Pt 12):2585-98.

21. Hoey JG, Summy J, Flynn DC. Chimeric constructs containing the SH4/Unique domains of cYes can restrict the ability of Src(527F) to 
upregulate heme oxygenase-1 expression efficiently. Cell Signal. 2000;12(9-10):691-701.

22. Arbesu M, Maffei M, Cordeiro TN, Teixeira JM, Perez Y, Bernado P, et al. The unique domain forms a fuzzy intramolecular complex in Src family kinases. Structure. 2017;25(4):630-404.

23. Kaplan JM, Varmus HE, Bishop JM. The src protein contains multiple domains for specific attachment to membranes. Mol Cell Biol. 1990;10(3):1000-9.

24. Hashmi F, Mollapour M, Bratslavsky G, Bourboulia D. MMPs, tyrosine kinase signaling and extracellular matrix proteolysis in kidney cancer. Urol Oncol. 2020.

25. Resh MD. Myristylation and palmitylation of Src family members: the fats of the matter. Cell. 1994;76(3):411-3.

26. Kim S, Alsaidan OA, Goodwin O, Li Q, Sulejmani E, Han Z, et al. Blocking myristoylation of Src inhibits its kinase activity and suppresses prostate cancer progression. Cancer Res. 2017;77(24):6950-62.

27. Shenoy-Scaria AM, Gauen LK, Kwong J, Shaw AS, Lublin DM. Palmitylation of an amino-terminal cysteine motif of protein tyrosine kinases p56lck and p59fyn mediates interaction with glycosyl-phosphatidylinositol-anchored proteins. Mol Cell Biol. 1993;13(10):6385-92.

28. KoegI M, Zlatkine P, Ley SC, Courtneidge SA, Magee Al. Palmitoylation of multiple Src-family kinases at a homologous $\mathrm{N}$-terminal motif. Biochem J. 1994;303(Pt 3):749-53.

29. Kim PW, Sun ZY, Blacklow SC, Wagner G, Eck MJ. A zinc clasp structure tethers Lck to T cell coreceptors CD4 and CD8. Science. 2003;301(5640):1725-8.

30. Scanlon DP, Bah A, Krzeminski M, Zhang W, Leduc-Pessah HL, Dong YN, et al. An evolutionary switch in ND2 enables Src kinase regulation of NMDA receptors. Nat Commun. 2017;8:15220.

31. Gingrich JR, Pelkey KA, Fam SR, Huang Y, Petralia RS, Wenthold RJ, et al. Unique domain anchoring of Src to synaptic NMDA receptors via the mitochondrial protein NADH dehydrogenase subunit 2. Proc Natl Acad Sci USA. 2004;101(16):6237-42.

32. Brown MT, Cooper JA. Regulation, substrates and functions of src. Biochim Biophys Acta. 1996;1287(2-3):121-49.

33. Eck MJ, Atwell SK, Shoelson SE, Harrison SC. Structure of the regulatory domains of the Src-family tyrosine kinase Lck. Nature. 1994:368(6473):764-9.

34. Banjade S, Wu Q, Mittal A, Peeples WB, Pappu RV, Rosen MK. Conserved interdomain linker promotes phase separation of the multivalent adaptor protein Nck. Proc Natl Acad Sci USA. 2015;112(47):E6426-35.

35. Kurochkina N, Guha U. SH3 domains: modules of protein-protein interactions. Biophys Rev. 2013;5(1):29-39.

36. Sicheri F, Moarefi I, Kuriyan J. Crystal structure of the Src family tyrosine kinase Hck. Nature. 1997;385(6617):602-9.

37. Jaber Chehayeb R, Boggon TJ. SH2 Domain Binding: Diverse FLVRs of Partnership. Front Endocrinol (Lausanne). 2020;11:575220.

38. Boggon TJ, Eck MJ. Structure and regulation of Src family kinases. Oncogene. 2004;23(48):7918-27.

39. Jeschke M, Brandi ML, Susa M. Expression of Src family kinases and their putative substrates in the human preosteoclastic cell line FLG 291. J Bone Miner Res. 1998;13(12):1880-9.

40. Kuga T, Nakayama Y, Hoshino M, Higashiyama Y, Obata Y, Matsuda D, et al. Differential mitotic activation of endogenous C-Src, c-Yes, and Lyn in HeLa cells. Arch Biochem Biophys. 2007:466(1):116-24.

41. Kaplan KB, Swedlow JR, Varmus HE, Morgan DO. Association of p60c-src with endosomal membranes in mammalian fibroblasts. J Cell Biol. 1992:118(2):321-33.

42. Kaplan KB, Bibbins KB, Swedlow JR, Arnaud M, Morgan DO, Varmus HE. Association of the amino-terminal half of c-Src with focal adhesions alters their properties and is regulated by phosphorylation of tyrosine 527. EMBO J. 1994;13(20):4745-56.

43. Robbins SM, Quintrell NA, Bishop JM. Myristoylation and differential palmitoylation of the HCK protein-tyrosine kinases govern their attachment to membranes and association with caveolae. Mol Cell Biol. 1995:15(7):3507-15

44. Lowell CA, Niwa M, Soriano P, Varmus HE. Deficiency of the Hck and Src tyrosine kinases results in extreme levels of extramedullary hematopoiesis. Blood. 1996;87(5):1780-92.
45. Ikeda K, Nakayama Y, Togashi Y, Obata Y, Kuga T, Kasahara K, et al. Nuclear localization of Lyn tyrosine kinase mediated by inhibition of its kinase activity. Exp Cell Res. 2008;314(18):3392-404.

46. Sanchez-Pozo J, Baker-Williams AJ, Woodford MR, Bullard R, Wei B, Mollapour M, et al. Extracellular phosphorylation of TIMP-2 by secreted c-Src tyrosine kinase controls MMP-2 activity. iScience. 2018;1:87-96.

47. Tanaka K, Ito Y, Kajiwara K, Nada S, Okada M. Ubiquitination of Src promotes its secretion via small extracellular vesicles. Biochem Biophys Res Commun. 2020.

48. Rogers JA. Materials science. Nanometer-scale printing. Science. 2012:337(6101):1459-60.

49. Parsons SJ, Parsons JT. Src family kinases, key regulators of signal transduction. Oncogene. 2004;23(48):7906-9.

50. Thiery JP. Epithelial-mesenchymal transitions in development and pathologies. Curr Opin Cell Biol. 2003;15(6):740-6.

51. Chen SC, Liao TT, Yang MH. Emerging roles of epithelial-mesenchymal transition in hematological malignancies. J Biomed Sci. 2018;25(1):37.

52. Du B, Shim JS. Targeting epithelial-mesenchymal transition (EMT) to overcome drug resistance in cancer. Molecules (Basel, Switzerland) 2016;21(7)

53. Yao D, Dai C, Peng S. Mechanism of the mesenchymal-epithelial transition and its relationship with metastatic tumor formation. Mol Cancer Res. 2011;9(12):1608-20.

54. Jefferson JJ, Leung CL, Liem RK. Plakins: goliaths that link cell junctions and the cytoskeleton. Nat Rev Mol Cell Biol. 2004;5(7):542-53.

55. Frame MC, Simpson K, Fincham VJ, Crouch DH. Separation of V-Srcinduced mitogenesis and morphological transformation by inhibition of AP-1. Mol Biol Cell. 1994;5(11):1177-84.

56. Herranz N, Pasini D, Diaz VM, Franci C, Gutierrez A, Dave N, et al. Polycomb complex 2 is required for E-cadherin repression by the Snail1 transcription factor. Mol Cell Biol. 2008;28(15):4772-81.

57. Cano A, Perez-Moreno MA, Rodrigo I, Locascio A, Blanco MJ, del Barrio $M G$, et al. The transcription factor snail controls epithelial-mesenchymal transitions by repressing E-cadherin expression. Nat Cell Biol. 2000;2(2):76-83.

58. Batlle E, Sancho E, Franci C, Dominguez D, Monfar M, Baulida J, et al. The transcription factor snail is a repressor of $\mathrm{E}$-cadherin gene expression in epithelial tumour cells. Nat Cell Biol. 2000;2(2):84-9.

59. Sanchez-Tillo E, Lazaro A, Torrent R, Cuatrecasas M, Vaquero EC, Castells $A$, et al. ZEB1 represses E-cadherin and induces an EMT by recruiting the SWI/SNF chromatin-remodeling protein BRG1. Oncogene. 2010:29(24):3490-500.

60. Yang MH, Hsu DS, Wang HW, Wang HJ, Lan HY, Yang WH, et al. Bmi1 is essential in Twist1-induced epithelial-mesenchymal transition. Nat Cell Biol. 2010;12(10):982-92.

61. Behrens J, Vakaet L, Friis R, Winterhager E, Van Roy F, Mareel MM, et al. Loss of epithelial differentiation and gain of invasiveness correlates with tyrosine phosphorylation of the E-cadherin/beta-catenin complex in cells transformed with a temperature-sensitive v-SRC gene. J Cell Biol. 1993;120(3):757-66

62. van Roy F, Berx G. The cell-cell adhesion molecule E-cadherin. Cell Mol Life Sci. 2008;65(23):3756-88.

63. Shibamoto S, Hayakawa M, Takeuchi K, Hori T, Miyazawa K, Kitamura N, et al. Association of p120, a tyrosine kinase substrate, with E-cadherin/ catenin complexes. J Cell Biol. 1995;128(5):949-57.

64. Barry AK, Tabdili H, Muhamed I, Wu J, Shashikanth N, Gomez GA, et al. alpha-catenin cytomechanics-role in cadherin-dependent adhesion and mechanotransduction. J Cell Sci. 2014;127(Pt 8):1779-91.

65. Desai R, Sarpal R, Ishiyama N, Pellikka M, Ikura M, Tepass U. Monomeric alpha-catenin links cadherin to the actin cytoskeleton. Nat Cell Biol. 2013;15(3):261-73.

66. Yamaguchi $\mathrm{H}$, Condeelis J. Regulation of the actin cytoskeleton in cancer cell migration and invasion. Biochim Biophys Acta. 2007;1773(5):642-52.

67. Goley ED, Welch MD. The ARP2/3 complex: an actin nucleator comes of age. Nat Rev Mol Cell Biol. 2006;7(10):713-26.

68. Yamazaki D, Oikawa T, Takenawa T. Rac-WAVE-mediated actin reorganization is required for organization and maintenance of cell-cell adhesion. J Cell Sci. 2007;120(Pt 1):86-100.

69. Ryu JR, Echarri A, Li R, Pendergast AM. Regulation of cell-cell adhesion by Abi/Diaphanous complexes. Mol Cell Biol. 2009;29(7):1735-48. 
70. Innocenti M, Gerboth S, Rottner K, Lai FP, Hertzog M, Stradal TE, et al. Abi1 regulates the activity of N-WASP and WAVE in distinct actin-based processes. Nat Cell Biol. 2005;7(10):969-76.

71. Dubielecka PM, Machida K, Xiong X, Hossain S, Ogiue-Ikeda M, Carrera AC, et al. Abi1/Hssh3bp1 pY213 links Abl kinase signaling to p85 regulatory subunit of $\mathrm{PI}-3$ kinase in regulation of macropinocytosis in LNCaP cells. FEBS Lett. 2010;584(15):3279-86.

72. Xiong X, Cui P, Hossain S, Xu R, Warner B, Guo X, et al. Allosteric inhibition of the nonMyristoylated $\mathrm{C}-\mathrm{Abl}$ tyrosine kinase by phosphopeptides derived from Abi1/Hssh3bp1. Biochim Biophys Acta. 2008; 1783(5):737-47.

73. Nath D, Li X, Mondragon C, Post D, Chen M, White JR, et al. Abi1 loss drives prostate tumorigenesis through activation of EMT and noncanonical WNT signaling. Cell Commun Signal. 2019;17(1):120.

74. Chen CL, Wang SH, Chan PC, Shen MR, Chen HC. Phosphorylation of E-cadherin at threonine 790 by protein kinase Cdelta reduces betacatenin binding and suppresses the function of E-cadherin. Oncotarget. 2016;7(24):37260-76.

75. Castano J, Solanas G, Casagolda D, Raurell I, Villagrasa P, Bustelo XR, et al. Specific phosphorylation of p120-catenin regulatory domain differently modulates its binding to RhoA. Mol Cell Biol. 2007;27(5):1745-57.

76. Yoo Y, Ho HJ, Wang C, Guan JL. Tyrosine phosphorylation of cofilin at Y68 by v-Src leads to its degradation through ubiquitin-proteasome pathway. Oncogene. 2010;29(2):263-72.

77. Ichetovkin I, Grant W, Condeelis J. Cofilin produces newly polymerized actin filaments that are preferred for dendritic nucleation by the Arp2/3 complex. Curr Biol. 2002;12(1):79-84.

78. Aigner K, Dampier B, Descovich L, Mikula M, Sultan A, Schreiber M, et al. The transcription factor ZEB1 (deltaEF1) promotes tumour cell dedifferentiation by repressing master regulators of epithelial polarity. Oncogene. 2007;26(49):6979-88.

79. Spaderna S, Schmalhofer O, Wahlbuhl M, Dimmler A, Bauer K, Sultan A, et al. The transcriptional repressor ZEB1 promotes metastasis and loss of cell polarity in cancer. Cancer Res. 2008;68(2):537-44.

80. Playford MP, Schaller MD. The interplay between Src and integrins in normal and tumor biology. Oncogene. 2004;23(48):7928-46.

81. Lamouille $S, X u$ J, Derynck R. Molecular mechanisms of epithelial-mesenchymal transition. Nat Rev Mol Cell Biol. 2014;15(3):178-96.

82. Eckert MA, Lwin TM, Chang AT, Kim J, Danis E, Ohno-Machado L, et al. Twist1-induced invadopodia formation promotes tumor metastasis. Cancer Cell. 2011;19(3):372-86.

83. Eddy RJ, Weidmann MD, Sharma VP, Condeelis JS. Tumor cell invadopodia: invasive protrusions that orchestrate metastasis. Trends Cell Biol. 2017;27(8):595-607.

84. Linder S, Aepfelbacher M. Podosomes: adhesion hot-spots of invasive cells. Trends Cell Biol. 2003;13(7):376-85.

85. Hoshino D, Branch KM, Weaver AM. Signaling inputs to invadopodia and podosomes. J Cell Sci. 2013;126(Pt 14):2979-89.

86. Artym VV, Zhang Y, Seillier-Moiseiwitsch F, Yamada KM, Mueller SC. Dynamic interactions of cortactin and membrane type 1 matrix metalloproteinase at invadopodia: defining the stages of invadopodia formation and function. Cancer Res. 2006;66(6):3034-43.

87. Mizutani K, Miki H, He H, Maruta H, Takenawa T. Essential role of neural Wiskott-Aldrich syndrome protein in podosome formation and degradation of extracellular matrix in src-transformed fibroblasts. Cancer Res. 2002;62(3):669-74.

88. Wu H, Reynolds AB, Kanner SB, Vines RR, Parsons JT. Identification and characterization of a novel cytoskeleton-associated pp60src substrate. Mol Cell Biol. 1991;11(10):5113-24.

89. Weaver AM, Karginov AV, Kinley AW, Weed SA, Li Y, Parsons JT, et al. Cortactin promotes and stabilizes Arp2/3-induced actin filament network formation. Curr Biol. 2001;11(5):370-4.

90. Tehrani S, Tomasevic N, Weed S, Sakowicz R, Cooper JA. Src phosphorylation of cortactin enhances actin assembly. Proc Natl Acad Sci USA. 2007;104(29):11933-8.

91. Zahedi RP, Lewandrowski U, Wiesner J, Wortelkamp S, Moebius J, Schutz C, et al. Phosphoproteome of resting human platelets. J Proteome Res. 2008;7(2):526-34

92. Burger KL, Learman BS, Boucherle AK, Sirintrapun SJ, Isom S, Diaz B, et al. Src-dependent Tks5 phosphorylation regulates invadopodiaassociated invasion in prostate cancer cells. Prostate. 2014;74(2):134-48.
93. Seals DF, Azucena EF Jr, Pass I, Tesfay L, Gordon R, Woodrow M, et al. The adaptor protein Tks5/Fish is required for podosome formation and function, and for the protease-driven invasion of cancer cells. Cancer Cell. 2005;7(2):155-65

94. Nakahara H, Howard L, Thompson EW, Sato H, Seiki M, Yeh Y, et al. Transmembrane/cytoplasmic domain-mediated membrane type 1-matrix metalloprotease docking to invadopodia is required for cell invasion. Proc Natl Acad Sci USA. 1997;94(15):7959-64.

95. Monsky WL, Kelly T, Lin CY, Yeh Y, Stetler-Stevenson WG, Mueller SC, et al. Binding and localization of M(r) 72,000 matrix metalloproteinase at cell surface invadopodia. Cancer Res. 1993;53(13):3159-64.

96. Li H, Qiu Z, Li F, Wang C. The relationship between MMP-2 and MMP-9 expression levels with breast cancer incidence and prognosis. Oncol Lett. 2017;14(5):5865-70.

97. Cortes-Reynosa P, Robledo T, Macias-Silva M, Wu SV, Salazar EP. Src kinase regulates metalloproteinase- 9 secretion induced by type IV collagen in MCF-7 human breast cancer cells. Matrix Biol. 2008;27(3):220-31.

98. Sun X, Li C, Zhuang C, Gilmore WC, Cobos E, Tao Y, et al. Abl interactor 1 regulates Src-Id1-matrix metalloproteinase 9 axis and is required for invadopodia formation, extracellular matrix degradation and tumor growth of human breast cancer cells. Carcinogenesis. 2009;30(12):2109-16.

99. Serrano-Gomez SJ, Maziveyi M, Alahari SK. Regulation of epithelialmesenchymal transition through epigenetic and post-translational modifications. Mol Cancer. 2016;15:18.

100. Wendt MK, Balanis N, Carlin CR, Schiemann WP. STAT3 and epithelialmesenchymal transitions in carcinomas. JAKSTAT. 2014;3(1):e28975.

101. Feldker N, Ferrazzi F, Schuhwerk H, Widholz SA, Guenther K, Frisch I, et al. Genome-wide cooperation of EMT transcription factor ZEB1 with YAP and AP-1 in breast cancer. EMBO J. 2020;39(17):e103209.

102. Stemmer V, de Craene B, Berx G, Behrens J. Snail promotes Wnt target gene expression and interacts with beta-catenin. Oncogene. 2008;27(37):5075-80.

103. Balsamo J, Arregui C, Leung T, Lilien J. The nonreceptor protein tyrosine phosphatase PTP1B binds to the cytoplasmic domain of $\mathrm{N}$-cadherin and regulates the cadherin-actin linkage. J Cell Biol. 1998;143(2):523-32.

104. Byers LA, Sen B, Saigal B, Diao L, Wang J, Nanjundan M, et al. Reciprocal regulation of $\mathrm{C}$-Src and STAT3 in non-small cell lung cancer. Clin Cancer Res. 2009;15(22):6852-61.

105. Mahajan NP, Liu Y, Majumder S, Warren MR, Parker CE, Mohler JL, et al. Activated Cdc42-associated kinase Ack1 promotes prostate cancer progression via androgen receptor tyrosine phosphorylation. Proc Natl Acad Sci USA. 2007;104(20):8438-43.

106. Guo Z, Dai B, Jiang T, Xu K, Xie Y, Kim O, et al. Regulation of androgen receptor activity by tyrosine phosphorylation. Cancer Cell. 2006;10(4):309-19.

107. Shipitsin M, Campbell LL, Argani P, Weremowicz S, Bloushtain-Qimron $\mathrm{N}$, Yao J, et al. Molecular definition of breast tumor heterogeneity. Cancer Cell. 2007;11(3):259-73.

108. Galliher AJ, Schiemann WP. Src phosphorylates Tyr284 in TGF-beta type II receptor and regulates TGF-beta stimulation of p38 MAPK during breast cancer cell proliferation and invasion. Cancer Res. 2007;67(8):3752-8.

109. Zhang H, Davies KJ, Forman HJ. TGFbeta1 rapidly activates Src through a non-canonical redox signaling mechanism. Arch Biochem Biophys. 2015:568:1-7.

110. Park SS, Eom YW, Kim EH, Lee JH, Min DS, Kim S, et al. Involvement of $\mathrm{c}$-Src kinase in the regulation of TGF-beta1-induced apoptosis. Oncogene. 2004;23(37):6272-81.

111. Li X, Ortiz MA, Kotula L. The physiological role of Wnt pathway in normal development and cancer. Exp Biol Med (Maywood). 2020;245(5):411-26

112. Clevers H. Wnt/beta-catenin signaling in development and disease Cell. 2006;127(3):469-80.

113. Roura S, Miravet S, Piedra J, Garcia de Herreros A, Dunach M. Regulation of E-cadherin/Catenin association by tyrosine phosphorylation. J Biol Chem. 1999;274(51):36734-40.

114. Molenaar $M$, van de Wetering $M$, Oosterwegel M, Peterson-Maduro J, Godsave S, Korinek V, et al. XTcf-3 transcription factor mediates 
beta-catenin-induced axis formation in Xenopus embryos. Cell. 1996;86(3):391-9.

115. Brunet T, Bouclet A, Ahmadi P, Mitrossilis D, Driquez B, Brunet AC, et al. Evolutionary conservation of early mesoderm specification by mechanotransduction in Bilateria. Nat Commun. 2013:4:2821.

116. Karni R, Gus Y, Dor Y, Meyuhas O, Levitzki A. Active Src elevates the expression of beta-catenin by enhancement of cap-dependent translation. Mol Cell Biol. 2005;25(12):5031-9.

117. Wu Y, Ginther C, Kim J, Mosher N, Chung S, Slamon D, et al. Expression of Wnt3 activates Wnt/beta-catenin pathway and promotes EMT-like phenotype in trastuzumab-resistant HER2-overexpressing breast cancer cells. Mol Cancer Res. 2012;10(12):1597-606.

118. Gonzalez DM, Medici D. Signaling mechanisms of the epithelial-mesenchymal transition. Sci Signal. 2014;7(344):re8.

119. Batlle E, Clevers H. Cancer stem cells revisited. Nat Med 2017:23(10):1124-34

120. Derynck R, Muthusamy BP, Saeteurn KY. Signaling pathway cooperation in TGF-beta-induced epithelial-mesenchymal transition. Curr Opin Cell Biol. 2014;31:56-66.

121. Gujral TS, Chan M, Peshkin L, Sorger PK, Kirschner MW, MacBeath G. A noncanonical Frizzled2 pathway regulates epithelial-mesenchymal transition and metastasis. Cell. 2014;159(4):844-56.

122. Villarroel A, Del Valle-Perez B, Fuertes G, Curto J, Ontiveros N, Garcia de Herreros A, et al. Src and Fyn define a new signaling cascade activated by canonical and non-canonical Wnt ligands and required for gene transcription and cell invasion. Cell Mol Life Sci. 2020;77(5):919-35.

123. Niessen K, Fu Y, Chang L, Hoodless PA, McFadden D, Karsan A. Slug is a direct Notch target required for initiation of cardiac cushion cellularization. J Cell Biol. 2008;182(2):315-25.

124. Timmerman LA, Grego-Bessa J, Raya A, Bertran E, Perez-Pomares JM, Diez J, et al. Notch promotes epithelial-mesenchymal transition during cardiac development and oncogenic transformation. Genes Dev. 2004;18(1):99-115.

125. Wang Z, Li Y, Kong D, Sarkar FH. The role of Notch signaling pathway in epithelial-mesenchymal transition (EMT) during development and tumor aggressiveness. Curr Drug Targets. 2010;11(6):745-51.

126. Wang Z, Li Y, Kong D, Banerjee S, Ahmad A, Azmi AS, et al. Acquisition of epithelial-mesenchymal transition phenotype of gemcitabine-resistant pancreatic cancer cells is linked with activation of the notch signaling pathway. Cancer Res. 2009;69(6):2400-7.

127. Sahlgren C, Gustafsson MV, Jin S, Poellinger L, Lendahl U. Notch signaling mediates hypoxia-induced tumor cell migration and invasion. Proc Natl Acad Sci USA. 2008;105(17):6392-7.

128. LaFoya B, Munroe JA, Pu X, Albig AR. Src kinase phosphorylates Notch1 to inhibit MAML binding. Sci Rep. 2018;8(1):15515.

129. Hynes NE, Lane HA. ERBB receptors and cancer: the complexity of targeted inhibitors. Nat Rev Cancer. 2005;5(5):341-54.

130. Sabbah DA, Hajjo R, Sweidan K. Review on epidermal growth factor receptor (EGFR) structure, signaling pathways, interactions, and recent updates of EGFR inhibitors. Curr Top Med Chem. 2020;20(10):815-34.

131. Yarden Y, Sliwkowski MX. Untangling the ErbB signalling network. Nat Rev Mol Cell Biol. 2001;2(2):127-37.

132. Ogiso H, Ishitani R, Nureki O, Fukai S, Yamanaka M, Kim JH, et al. Crystal structure of the complex of human epidermal growth factor and recep tor extracellular domains. Cell. 2002;110(6):775-87.

133. Olayioye MA, Graus-Porta D, Beerli RR, Rohrer J, Gay B, Hynes NE. ErbB-1 and ErbB-2 acquire distinct signaling properties dependent upon their dimerization partner. Mol Cell Biol. 1998;18(9):5042-51.

134. Pinkas-Kramarski R, Soussan L, Waterman H, Levkowitz G, Alroy I, Klapper $\mathrm{L}$, et al. Diversification of Neu differentiation factor and epidermal growth factor signaling by combinatorial receptor interactions. EMBO J. 1996;15(10):2452-67.

135. Riese DJ 2nd, van Raaij TM, Plowman GD, Andrews GC, Stern DF. The cellular response to neuregulins is governed by complex interactions of the erbB receptor family. Mol Cell Biol. 1995;15(10):5770-6.

136. Kokai Y, Myers JN, Wada T, Brown VI, LeVea CM, Davis JG, et al. Synergistic interaction of p185c-neu and the EGF receptor leads to transformation of rodent fibroblasts. Cell. 1989;58(2):287-92.

137. Alimandi M, Romano A, Curia MC, Muraro R, Fedi P, Aaronson SA, et al. Cooperative signaling of ErbB3 and ErbB2 in neoplastic transformation and human mammary carcinomas. Oncogene. 1995;10(9):1813-21.
138. Wallasch C, Weiss FU, Niederfellner G, Jallal B, Issing W, Ullrich A Heregulin-dependent regulation of HER2/neu oncogenic signaling by heterodimerization with HER3. EMBO J. 1995:14(17):4267-75.

139. Chausovsky A, Waterman H, Elbaum M, Yarden Y, Geiger B, Bershadsky AD. Molecular requirements for the effect of neuregulin on cell spreading, motility and colony organization. Oncogene. 2000;19(7):878-88.

140. Kainulainen V, Sundvall M, Maatta JA, Santiestevan E, Klagsbrun M, Elenius K. A natural ErbB4 isoform that does not activate phosphoinositide 3-kinase mediates proliferation but not survival or chemotaxis. J Biol Chem. 2000;275(12):8641-9.

141. Vaskovsky A, Lupowitz Z, Erlich S, Pinkas-Kramarski R. ErbB-4 activation promotes neurite outgrowth in PC12 cells. J Neurochem. 2000;74(3):979-87.

142. Biscardi JS, Ishizawar RC, Silva CM, Parsons SJ. Tyrosine kinase signalling in breast cancer: epidermal growth factor receptor and c-Src interactions in breast cancer. Breast Cancer Res. 2000;2(3):203-10.

143. Karni R, Jove R, Levitzki A. Inhibition of pp60c-Src reduces Bcl-XL expression and reverses the transformed phenotype of cells overexpressing EGF and HER-2 receptors. Oncogene. 1999;18(33):4654-62.

144. Belsches-Jablonski AP, Biscardi JS, Peavy DR, Tice DA, Romney DA, Parsons SJ. Src family kinases and HER2 interactions in human breast cancer cell growth and survival. Oncogene. 2001;20(12):1465-75.

145. Ishizawar R, Parsons SJ. c-Src and cooperating partners in human cancer. Cancer Cell. 2004;6(3):209-14.

146. Maa MC, Leu TH, McCarley DJ, Schatzman RC, Parsons SJ. Potentiation of epidermal growth factor receptor-mediated oncogenesis by c-Src: implications for the etiology of multiple human cancers. Proc Natl Acad Sci USA. 1995;92(15):6981-5.

147. Muthuswamy SK, Muller WJ. Direct and specific interaction of c-Src with Neu is involved in signaling by the epidermal growth factor receptor. Oncogene. 1995:11(2):271-9.

148. Knebel A, Rahmsdorf HJ, Ullrich A, Herrlich P. Dephosphorylation of receptor tyrosine kinases as target of regulation by radiation, oxidants or alkylating agents. EMBO J. 1996;15(19):5314-25.

149. Prenzel N, Zwick E, Leserer M, Ullrich A. Tyrosine kinase signalling in breast cancer. Epidermal growth factor receptor: convergence point for signal integration and diversification. Breast Cancer Res. 2000;2(3):184-90.

150. Wu W, Graves LM, Gill GN, Parsons SJ, Samet JM. Src-dependent phosphorylation of the epidermal growth factor receptor on tyrosine 845 is required for zinc-induced Ras activation. J Biol Chem. 2002:277(27):24252-7.

151. Wilde A, Beattie EC, Lem L, Riethof DA, Liu SH, Mobley WC, et al. EGF receptor signaling stimulates SRC kinase phosphorylation of clathrin, influencing clathrin redistribution and EGF uptake. Cell. 1999;96(5):677-87.

152. Ahn S, Kim J, Lucaveche CL, Reedy MC, Luttrell LM, Lefkowitz RJ, et al. Src-dependent tyrosine phosphorylation regulates dynamin selfassembly and ligand-induced endocytosis of the epidermal growth factor receptor. J Biol Chem. 2002;277(29):26642-51.

153. Bao J, Gur G, Yarden Y. Src promotes destruction of c-Cbl: implications for oncogenic synergy between $\mathrm{Src}$ and growth factor receptors. Proc Natl Acad Sci USA. 2003:100(5):2438-43.

154. Janne PA. Ongoing first-line studies of epidermal growth factor receptor tyrosine kinase inhibitors in select patient populations. Semin Oncol. 2005;32(6 Suppl 10):S9-15.

155. Janne PA, Yang JC, Kim DW, Planchard D, Ohe Y, Ramalingam SS, et al. AZD9291 in EGFR inhibitor-resistant non-small-cell lung cancer. N Engl J Med. 2015;372(18):1689-99.

156. Marcotte R, Zhou L, Kim H, Roskelly CD, Muller WJ. c-Src associates with ErbB2 through an interaction between catalytic domains and confers enhanced transforming potential. Mol Cell Biol. 2009:29(21):5858-71.

157. Dillekas H, Rogers MS, Straume O. Are $90 \%$ of deaths from cancer caused by metastases? Cancer Med. 2019:8(12):5574-6.

158. Chaffer CL, Weinberg RA. A perspective on cancer cell metastasis. Science. 2011:331(6024):1559-64.

159. Shah AN, Gallick GE. Src, chemoresistance and epithelial to mesenchymal transition: are they related? Anticancer Drugs. 2007;18(4):371-5.

160. Smith BN, Bhowmick NA. Role of EMT in Metastasis and Therapy Resistance. J Clin Med. 2016:5(2). 
161. Zhang S, Yu D. Targeting Src family kinases in anti-cancer therapies: turning promise into triumph. Trends Pharmacol Sci. 2012;33(3):122-8.

162. Li C, lida M, Dunn EF, Ghia AJ, Wheeler DL. Nuclear EGFR contributes to acquired resistance to cetuximab. Oncogene. 2009;28(43):3801-13.

163. Dunn EF, lida M, Myers RA, Campbell DA, Hintz KA, Armstrong EA, et al. Dasatinib sensitizes KRAS mutant colorectal tumors to cetuximab. Oncogene. 2011;30(5):561-74.

164. Nagaraj NS, Washington MK, Merchant NB. Combined blockade of Srckinase and epidermal growth factor receptor with gemcitabine overcomes STAT3-mediated resistance of inhibition of pancreatic tumor growth. Clin Cancer Res. 2011;17(3):483-93.

165. Bai L, Yang JC, Ok JH, Mack PC, Kung HJ, Evans CP. Simultaneous targeting of Src kinase and receptor tyrosine kinase results in synergistic inhibition of renal cell carcinoma proliferation and migration. Int J Cancer. 2012;130(11):2693-702.

166. Ribeiro AS, Nobre AR, Mendes N, Almeida J, Vieira AF, Sousa B, et al. SRC inhibition prevents $\mathrm{P}$-cadherin mediated signaling and function in basal-like breast cancer cells. Cell Commun Signal. 2018;16(1):75.

167. Riggins RB, Thomas KS, Ta HQ, Wen J, Davis RJ, Schuh NR, et al. Physical and functional interactions between Cas and c-Src induce tamoxifen resistance of breast cancer cells through pathways involving epidermal growth factor receptor and signal transducer and activator of transcription $5 b$. Cancer Res. 2006;66(14):7007-15.

168. van Agthoven T, Sieuwerts AM, Meijer-van Gelder ME, Look MP, Smid M, Veldscholte J, et al. Relevance of breast cancer antiestrogen resistance genes in human breast cancer progression and tamoxifen resistance. $J$ Clin Oncol. 2009:27(4):542-9.

169. Vallabhaneni S, Nair BC, Cortez V, Challa R, Chakravarty D, Tekmal RR, et al. Significance of ER-Src axis in hormonal therapy resistance. Breast Cancer Res Treat. 2011;130(2):377-85

170. Schwarz U, Fox EM, Balko JM, Garrett JT, Kuba MG, Estrada MV, et al. LYN-activating mutations mediate antiestrogen resistance in estrogen receptor-positive breast cancer. J Clin Invest. 2014;124(12):5490-502.

171. Elias D, Vever H, Laenkholm AV, Gjerstorff MF, Yde CW, Lykkesfeldt AE, et al. Gene expression profiling identifies FYN as an important molecule in tamoxifen resistance and a predictor of early recurrence in patients treated with endocrine therapy. Oncogene. 2015;34(15):1919-27.

172. Tabaries S, Annis MG, Hsu BE, Tam CE, Savage P, Park M, et al. Lyn modulates Claudin-2 expression and is a therapeutic target for breast cancer liver metastasis. Oncotarget. 2015;6(11):9476-87.

173. Guan H, Zhou Z, Gallick GE, Jia SF, Morales J, Sood AK, et al. Targeting Lyn inhibits tumor growth and metastasis in Ewing's sarcoma. Mol Cancer Ther. 2008;7(7):1807-16.

174. Zhang S, Huang WC, Li P, Guo H, Poh SB, Brady SW, et al. Combating trastuzumab resistance by targeting SRC, a common node downstream of multiple resistance pathways. Nat Med. 2011;17(4):461-9.

175. Nagata Y, Lan KH, Zhou X, Tan M, Esteva FJ, Sahin AA, et al. PTEN activation contributes to tumor inhibition by trastuzumab, and loss of PTEN predicts trastuzumab resistance in patients. Cancer Cell. 2004:6(2):117-27.

176. Rexer BN, Ham AJ, Rinehart C, Hill S, Granja-Ingram Nde M, Gonzalez-Angulo AM, et al. Phosphoproteomic mass spectrometry profiling links Src family kinases to escape from HER2 tyrosine kinase inhibition. Oncogene. 2011:30(40):4163-74

177. Liang K, Esteva FJ, Albarracin C, Stemke-Hale K, LuY, Bianchini G, et al. Recombinant human erythropoietin antagonizes trastuzumab treatment of breast cancer cells via Jak2-mediated Src activation and PTEN inactivation. Cancer Cell. 2010;18(5):423-35.

178. Wang SE, Xiang B, Zent R, Quaranta V, Pozzi A, Arteaga CL. Transforming growth factor beta induces clustering of HER2 and integrins by activating Src-focal adhesion kinase and receptor association to the cytoskeleton. Cancer Res. 2009;69(2):475-82.

179. Zhu ML, Kyprianou N. Role of androgens and the androgen receptor in epithelial-mesenchymal transition and invasion of prostate cancer cells. FASEB J. 2010;24(3):769-77.

180. Liu Y, Karaca M, Zhang Z, Gioeli D, Earp HS, Whang YE. Dasatinib inhibits sitespecific tyrosine phosphorylation of androgen receptor by Ack1 and Src kinases. Oncogene. 2010;29(22):3208-16.

181. Mendiratta P, Mostaghel E, Guinney J, Tewari AK, Porrello A, Barry WT, et al. Genomic strategy for targeting therapy in castration-resistant prostate cancer. J Clin Oncol. 2009;27(12):2022-9.
182. Yu EY, Wilding G, Posadas E, Gross M, Culine S, Massard C, et al. Phase II study of dasatinib in patients with metastatic castration-resistant prostate cancer. Clin Cancer Res. 2009:15(23):7421-8.

183. Twardowski PW, Beumer JH, Chen CS, Kraft AS, Chatta GS, Mitsuhashi M, etal. A phase II trial of dasatinib in patients with metastatic castration-resistant prostate cancer treated previously with chemotherapy. Anticancer Drugs. 2013;24(7):743-53.

184. Haura EB, Tanvetyanon T, Chiappori A, Williams C, Simon G, Antonia S, et al. Phase I/II study of the Src inhibitor dasatinib in combination with erlotinib in advanced non-small-cell lung cancer. J Clin Oncol. 2010;28(8):1387-94.

185. Bauman JE, Duvvuri U, Gooding WE, Rath TJ, Gross ND, Song J, et al. Randomized, placebo-controlled window trial of EGFR, Src, or combined blockade in head and neck cancer. JCI Insight. 2017:2(6):e90449.

186. Stabile LP, Egloff AM, Gibson MK, Gooding WE, Ohr J, Zhou P, et al. IL6 is associated with response to dasatinib and cetuximab: Phase II clinical trial with mechanistic correlatives in cetuximab-resistant head and neck cancer. Oral Oncol. 2017:69:38-45.

187. Argiris A, Feinstein TM, Wang L, Yang T, Agrawal S, Appleman $\sqcup$, et al. Phase I and pharmacokinetic study of dasatinib and cetuximab in patients with advanced solid malignancies. Invest New Drugs. 2012;30(4):1575-84.

188. Weng CH, Chen LY, Lin YC, Shih JY, Lin YC, Tseng RY, et al. Epithelial-mesenchymal transition (EMT) beyond EGFR mutations per se is a common mechanism for acquired resistance to EGFR TKI. Oncogene. 2019;38(4):455-68

189. Fujita Y, Krause G, Scheffner M, Zechner D, Leddy HE, Behrens J, et al. Hakai, a c-Cbl-like protein, ubiquitinates and induces endocytosis of the E-cadherin complex. Nat Cell Biol. 2002;4(3):222-31.

190. Kruser TJ, Traynor AM, Wheeler DL. The use of single-agent dasatinib in molecularly unselected non-small-cell lung cancer patients. Expert Opin Investig Drugs. 2011;20(2):305-7.

191. Johnson FM, Bekele BN, Feng L, Wistuba I, Tang XM, Tran HT, et al. Phase II study of dasatinib in patients with advanced non-small-cell lung cancer. J Clin Oncol. 2010;28(30):4609-15.

192. Mayer EL, Baurain JF, Sparano J, Strauss L, Campone M, Fumoleau P, et al. A phase 2 trial of dasatinib in patients with advanced HER2-positive and/or hormone receptor-positive breast cancer. Clin Cancer Res. 2011;17(21):6897-904.

193. Powles T, Brown J, Larkin J, Jones R, Ralph C, Hawkins R, et al. A randomized, double-blind phase II study evaluating cediranib versus cediranib and saracatinib in patients with relapsed metastatic clear-cell renal cancer (COSAK). Ann Oncol. 2016;27(5):880-6.

194. Renouf DJ, Moore MJ, Hedley D, Gill S, Jonker D, Chen E, et al. A phase I/II study of the Src inhibitor saracatinib (AZD0530) in combination with gemcitabine in advanced pancreatic cancer. Invest New Drugs. 2012;30(2):779-86.

195. McNeish IA, Ledermann JA, Webber L, James L, Kaye SB, Hall M, et al. A randomised, placebo-controlled trial of weekly paclitaxel and saracatinib (AZD0530) in platinum-resistant ovarian, fallopian tube or primary peritoneal cancerdagger. Ann Oncol. 2014;25(10):1988-95.

196. Woodcock VK, Clive S, Wilson RH, Coyle VM, Stratford MRL, Folkes LK, et al. A first-in-human phase I study to determine the maximum tolerated dose of the oral Src/ABL inhibitor AZD0424. Br J Cancer. 2018;1 18(6):770-6.

197. Suwaki N, Vanhecke E, Atkins KM, Graf M, Swabey K, Huang P, et al. A HIFregulated VHL-PTP1B-Src signaling axis identifies a therapeutic target in renal cell carcinoma. Sci Transl Med. 2011;3(85):85-47.

198. Matrone MA, Whipple RA, Balzer EM, Martin SS. Microtentacles tip the balance of cytoskeletal forces in circulating tumor cells. Cancer Res. 2010;70(20):7737-41.

199. Martellucci S, Clementi L, Sabetta S, Mattei V, Botta L, Angelucci A. Src family kinases as therapeutic targets in advanced solid tumors: what we have learned so far. Cancers (Basel). 2020;12(6).

200. Elias D, Ditzel HJ. The potential of Src inhibitors. Aging (Albany NY). 2015;7(10):734-5.

201. Arcaroli J,Touban BM,Tan AC,Varella-Garcia M, Powell RW, Eckhardt SG, etal. Gene array and fluorescence in situ hybridization biomarkers of activity of saracatinib (AZD0530), a Src inhibitor, in a preclinical model of colorectal cancer. Clin Cancer Res. 2010;16(16):4165-77.

\section{Publisher's Note}

Springer Nature remains neutral with regard to jurisdictional claims in published maps and institutional affiliations. 